\title{
Plano regulador de 1948: diversificación espacial y exclusión social en Cartagena
}

\author{
Fabricio Valdelamar Villegas* \\ fayun68@gmail.com
}

Recibido: agosto de 2013

Aprobado: noviembre de 2013

Resumen: Para la segunda mitad del siglo Xx la ciudad de Cartagena adoptará el Plano regulador de 1948. Estrategia de la política urbana que respondía a los intereses de las autoridades nacionales y locales por hacer de la urbe un espacio funcional que respondiera a la necesidad de diversificar su aparato productivo. En este sentido la ciudad es zonificada en aras de lograr su mejor funcionamiento en el presente y en el futuro. Sin embargo, la renovación urbana sugerida en el plano fue parcial, pero, sobre todo, las innovaciones en cuanto equipamiento revelan el que parece ser el rasgo estructural de mayor duración durante la pasada centuria en la ciudad heroica: la exclusión social de vastos sectores de la "otra” Cartagena.

Palabras claves: Plano Regulador de 1948, funcionalismo arquitectónico, diversificación espacial, zonificación, exclusión social, Cartagena.

\section{8's Regulatory Plan: spatial diversification and social exclusion in Cartagena}

Abstract: For the second half of the twentieth century the city of Cartagena shall adopt the regulator Plano of 1948. Urban policy strategy responding to the interests of national and local authorities for making the city a functional space to respond to

\footnotetext{
* Licenciado en Ciencias de la Educación, especialidad en Ciencias Sociales, Universidad del Atlántico, Barranquilla (1992); Especialista en Pedagogía Para el Desarrollo del Aprendizaje Autónomo (UNAD 2003); Candidato a Magister en Historia de la Universidad Pedagógica y Tecnológica de Colombia, sede Tunja. Docente del Distrito de Cartagena y catedrático del Programa de Historia de la Facultad de Ciencias Humanas de la Universidad de Cartagena.
}

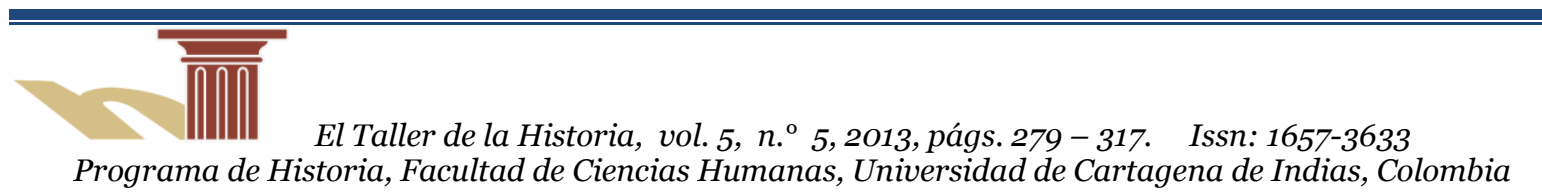


the need to diversify its productive apparatus. In this sense the city is zoned in order to achieve their best performance in the present and in the future. However, urban renewal was suggested in the flat was partial, but, above all, the innovations in equipment which reveal structural feature appears to be the longest during the past century in the heroic city: the social exclusion of large sectors of the "other" Cartagena.

Key words: 1948 Regulatory Plan, architectural functionalism, spatial diversification, zoning, social exclusion, Cartagena.

\section{Presentación}

nte las evidentes limitaciones resultantes de la aplicación del Plan Pearson de XX con una nueva propuesta de ordenamiento territorial. El Plano Regulador de 1948, elaborado por el arquitecto José María González Concha, sería la expresión de una renovada política con la firme pretensión de hacer de Cartagena una urbe funcional. Bajo las premisas del funcionalismo arquitectónico la ciudad se entendería como un espacio complejo en donde "la forma sigue a la función" y por lo tanto se hace pertinente su diversificación. La otrora aspiración de ciudad puerto marítimo es superada por el resoluto empeño de hacer del espacio citadino un lugar para habitar, trabajar, recrearse y circular. ${ }^{1}$

El Plano Regulador respondió a la necesidad de adaptar la ciudad a un viraje de estrategia económica, además de servir como instrumento para solucionar los problemas de infraestructura y urbanismo del presente y del futuro. Este giro urbanístico, propuesto en la ley sobre el fomento del desarrollo urbano en Colombia, ${ }^{2}$

\footnotetext{
${ }^{1}$ María de Jesús Fuente, Diccionario de historia urbana y urbanismo. El lenguaje de la ciudad en el tiempo, Madrid. Universidad Carlos III Boletín oficial del estado de Madrid, 1999, p.275

${ }^{2}$ Archivo Histórico de Cartagena (AHC), Diario Oficial, Enero-marzo de 1948. Ley 88 de 1947. Bogotá, 8 de enero de 1948. Para obtener una visión de los problemas que en la práctica debieron afrontar las autoridades nacionales y locales, de otras regiones, en la vigencia de planes urbanísticos anteriores a 1948 ver: León Darío Espinosa, "El Plan Piloto de Cali 1950”, en Bitácora n. ${ }^{10}$, Bogotá, Universidad Nacional, 2006, pp.222-232; Carlos Torres Tovar, "Reflexiones sobre el contexto del urbanismo en Colombia", en Urbanismo, maestría en urbanismo, pp.122-137 http://goo.gl/pRNroM.
} 
responde a la introducción en el ámbito nacional de la tendencia funcionalista, específicamente de los principios establecidos en la "Carta de Atenas" en la que se expresa que:

Las claves del urbanismo se encuentran en las cuatro funciones: habitar, trabajar, recrearse y circular. El urbanismo tiene cuatro objetivos que son: Primero. Asegurar a los hombres alojamiento sano, es decir, lugares en que el espacio, el aire puro y el sol, estás tres condiciones de naturaleza estén ampliamente aseguradas. Segundo. Organizar los lugares de trabajo de modo que éste, en vez de ser una penosa sujeción, recupere su carácter de actividad humana natural. Tercero. Prever las instalaciones necesarias para una buena utilización de las horas libres, haciéndolas beneficiosas y fecundas. Cuarto. Establecer el vínculo entre diversas organizaciones por medio de una red circulatoria que asegure los intercambios sin dejar de respetar las prerrogativas de cada una de ellas. Estos cuatro objetivos son las cuatro claves del urbanismo. ${ }^{3}$

El objetivo de este artículo es analizar el viraje que, a mediados del siglo xx, adopta la renovación espacial de la ciudad y el consecuente proceso de exclusión social que se deriva de la pretendida innovación. En este sentido se explican las medidas asumidas por la administración para lograr la diversificación económica; las transformaciones tanto en la infraestructura como en la superestructura urbana; así como los procesos de marginación y exclusión social que tienen ocurrencia durante la vigencia del plano regulador. Cabe advertir que la perspectiva, desde la cual se aborda la problemática en cuestión, es histórica en el entendido que la ciudad es un espacio social e históricamente construido. ${ }^{4}$

${ }^{3}$ C. Torres Tovar, Reflexiones sobre el contexto del urbanismo en Colombia, p.245.

${ }^{4}$ Lewis Munford afirma que el pensamiento toma forma en la ciudad y a su vez la forma urbana condiciona el pensamiento. Porque el espacio, no menos que el tiempo, es reorganizado ingeniosamente en la ciudad; en las líneas y contornos de los muros, en los planos horizontales y líneas verticales, en el utilizar o contrastar la conformación natural. Lewis Munford, La ciudad en la historia, su origen, transformaciones y perspectivas (Colmena o ciudad), tomo II, Eds. infinito, 1996. p 14; Carmen Hernández y Nellys Bohórquez, Barrios populares. Una forma de construir ciudad en Cartagena de Indias. Casos: Pekín, Pueblo Nuevo y Boquetillo 189o-1939, tesis de grado, Universidad de Cartagena, 2008; Orlando de Ávila, Políticas Urbanas, Pobreza y Exclusión Social en Cartagena: el caso de Chambacú, Tesis de grado para optar el título de Historiador. Universidad de Cartagena, 2008; Germán Mejía, "Pensando la Historia Urbana", en Germán Mejía y Fabio Zambrano (eds.), La ciudad y las Ciencias Sociales. Ensayos y aproximaciones, Bogotá, Universidad Javeriana, 2000, pp.47-73; y también Alfonso Álvarez Medina, Problemas de investigación en "Historia urbanística", en Historia Urbana. Revista de historia de las ideas y de las transformaciones urbanas n. ${ }^{\circ}$, Valencia, Universidad Politécnica de Valencia, 1992, pp.83-102, citados en Adriana Suárez 
En la primera sección del artículo se hace un recorrido panorámico por las recomendaciones del Plano Regulador en asuntos como el plan vial, terrestre y fluvial, así como la propuesta de zonificación de la urbe en áreas turísticas, industriales, comerciales, portuarias y residenciales. Igualmente se relaciona lo insinuado para los sectores de la salud y la educación, además de lo concerniente a la base naval y el hospital militar. En la segunda parte del artículo se contrastan las propuestas del Plano Regulador con la cotidianidad de los sectores populares. En esa perspectiva se confrontan, con las denuncias de la prensa de la época, las decisiones adoptadas por la administración local en materia de equipamiento urbano. Finalmente, se concluye con una reflexión sobre la manera cómo opera el proceso de exclusión social en el contexto del Plano Regulador.

Mayorga, La ciudad de los elegidos. Crecimiento urbano, jerarquización social y poder político. Bogotá (1910-1950), Bogotá, Ed. Guadalupe Ltda., 2006, p.15; Cabe aclarar que para algunos pensadores como Alfonso Álvarez existe una clara distinción entre Historia urbana e Historia urbanística que no persiguen lo mismo, ya que para la primera "estudia los "hechos urbanos" desde perspectivas sociales, económicas, políticas, etc., sin afrontar el "proceso histórico de construcción de la ciudad", mientras la segunda, "trata del conocimiento de las intervenciones urbanísticas a que han sido sometidas las ciudades" a lo largo del tiempo. Alfonso Álvarez, "La necesaria componente espacial en la historia urbana”, en Carlos Sambricio (ed.), La historia Urbana, Colección Ayer n. ${ }^{\circ} 23$, Madrid, Marcial Pons, 1996. Sin embargo los balances historiográficos recientes sobre historia urbana rescatan la evolución que ha tenido este campo de la disciplina histórica en la forma de abordar el objeto de estudio. La historia urbana que hoy se elabora es producto de un diálogo entre saberes de distintos dominios, de la arquitectura, la psicología, la antropología, la filosofía, la sociología, la historia y los estudios culturales. Para un acercamiento a estos balances Ver: Nicolás Gualteros Trujillo, (ed.), Itinerarios Urbanos: París, La Habana, Bogotá: narraciones, identidades y cartografía, Bogotá, Universidad Javeriana, 2006. Peter Krieger, Paisajes Urbanos: Imagen y memoria, México, UNAM, 2006. Cesare de Seta, La ciudad europea del siglo XV al XX, Madrid, Ed. Istmo, 2002. Saskia Sassen, Territorio, Autoridad y Derechos. De los ensamblajes medievales a los ensamblajes globales, Madrid, Katz Eds., 2010. Estudios como los de Humberto Triana y Antorveza, Cultura del tugurio en Cartagena (1974); Betty Cárdenas y Alba Verbel (1984); Fernando Viviescas, La Formalización del espacio y la cultura urbana en Colombia: la perspectiva de la constitución de 1991 (1991); Alfonso Torres, La ciudad en la sombra (2000); Julián Arturo, Pobladores Urbanos. Ciudades y Espacio (1994); Fabio Zambrano, La ciudad en la historia (1993), entre otros, desde perspectivas arquitectónicas-urbanísticas, antropológicas e históricas, también constituyen un aporte de gran trascendencia para comprender, comparativamente, la dinámica de las urbes del país. 


\section{1.- Diversificando estrategias}

Para la segunda mitad del siglo xx Cartagena inicia su segunda época de oro, planificada para lograr el fortalecimiento de su condición portuaria, el desarrollo de su potencial turístico y, con la aparición de Mamonal, constituirla en centro manufacturero. Tal fue el ideario de las autoridades locales. ${ }^{5}$ Con este objetivo, la administración inicia un segundo proyecto de adecuación y reestructuración de la infraestructura, y de la superestructura, urbana de la ciudad, propósito que inicia con la aplicación del Plano Regulador de Cartagena de 1948.6 El plan se centraba en seis aspectos fundamentales, que seguían las directrices de la clase dirigente e industrial de la ciudad y del país. Estos nuevos atributos permiten apreciar que: "[...] Cartagena esta llamada a ser: a) Puerto marítimo y fluvial de primer orden. b) Terminal ferroviario troncal. c) Plaza comercial. d) Ciudad de turismo. e) Base naval nacional. f) Ciudad olímpica". ${ }^{7}$

Para cumplir con estos objetivos debían realizarse una serie de obras que permitieran ampliar, rectificar y construir, las vías de comunicación terrestre y fluvial de la ciudad. Así mismo, debía zonificarse la localidad en áreas en donde quedara definido su carácter urbano, esto es: áreas turísticas, industriales, comerciales, portuarias y residenciales.

En este periodo, Cartagena, se ubica como el segundo puerto del territorio nacional, luego de Barranquilla, no obstante su actividad portuaria sigue generando el principal aporte a la economía local, y su contribución a nivel nacional sigue siendo significativa, tal como lo señalan Báez Ramírez y Calvo Stevenson: "[...] Entre 1966 y 1996 la aduana de Cartagena movilizó, en promedio, 34\% del comercio colombiano de exportación e importación [...] mientras que el volumen del comercio del país, como un todo, creció durante ese lapso siete veces, el movimiento de

\footnotetext{
${ }^{5}$ Directorio industrial y comercial de Bolívar, Cartagena, ANDI, 1982, pp.28 y 30.

${ }^{6} \mathrm{El} 20$ de diciembre de 1946 quedó definitivamente aprobado el contrato entre la gobernación de Bolívar y el arquitecto José María González Concha para la elaboración del Plano Regulador de Cartagena. Archivo Personal, Memoria explicativa del Plano Regulador de José María González Concha. (documento cedido por la historiadora María Teresa Ripoll), Capítulo I, Cartagena, 2011, p.5 recto. (En adelante se citará como A. P. Memoria explicativa del Plano Regulador).
}

${ }^{7}$ A. P., Memoria explicativa del Plano Regulador, p.24. 
carga de Cartagena aumento 18 veces" ${ }^{8}$ Los autores abonan a estos resultados varias causas probables: La sedimentación del puerto de Barranquilla, que ocasionó represamiento de mercancías en el vecino puerto; el incremento y la diversidad de las exportaciones del país y; el crecimiento industrial en Mamonal, entre otros. ${ }^{9}$ Sin embargo, se presentarían a lo largo del siglo, algunos sucesos que determinaron procesos de avance y retroceso de dicha actividad en la ciudad.

En 1930 un voraz incendio consumió en su totalidad el muelle de La Machina, ubicado en la península de Boca Grande, lo que acabaría con los dineros invertidos por la ANDIAN y por la nación en dicho proyecto, que había sido contemplado en el Plan Pearson de 1914. El nuevo Terminal Marítimo, empezaría a operar en Manga para 1934, con una infraestructura más moderna y con un calado mucho más profundo que el de la bahía de Las Ánimas.

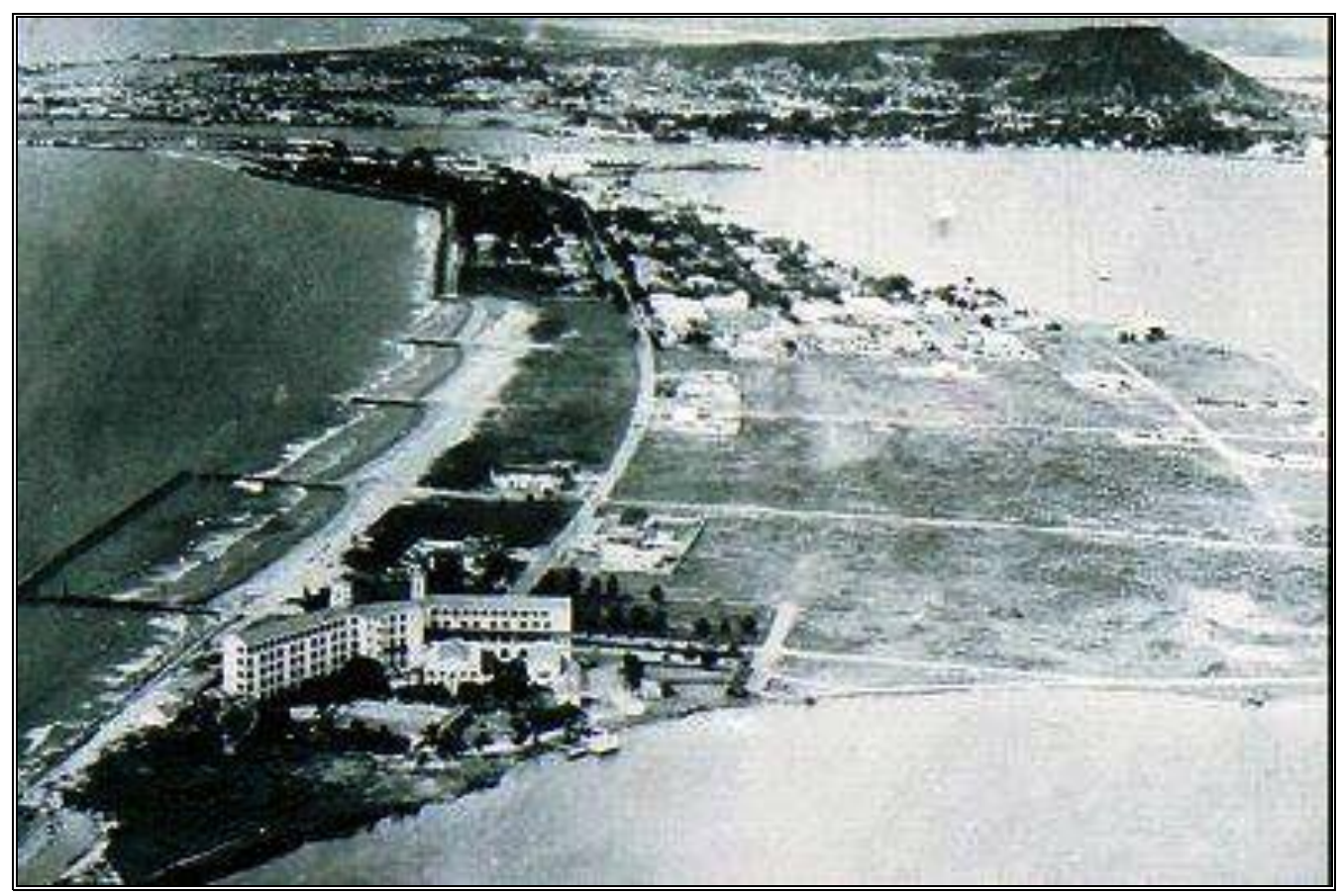

Imagen 1. En primer plano el Hotel Caribe. Al fondo se aprecia la urbanización de Boca Grande, 1946. (Colección particular)

\footnotetext{
${ }^{8}$ Javier Báez y Haroldo Calvo Stevenson, "La economía de Cartagena en la segunda mitad del siglo Xx: Diversificación y rezago", en Haroldo Calvo Stevenson y Adolfo Meisel Roca (comps.), Cartagena de Indias en el siglo XX, Cartagena, Banco de la República, 2000, pp.84-85.

${ }^{9}$ J. Báez y H. Calvo, "La economía de Cartagena en la segunda mitad del siglo xx: Diversificación y rezago", p.85.
} 


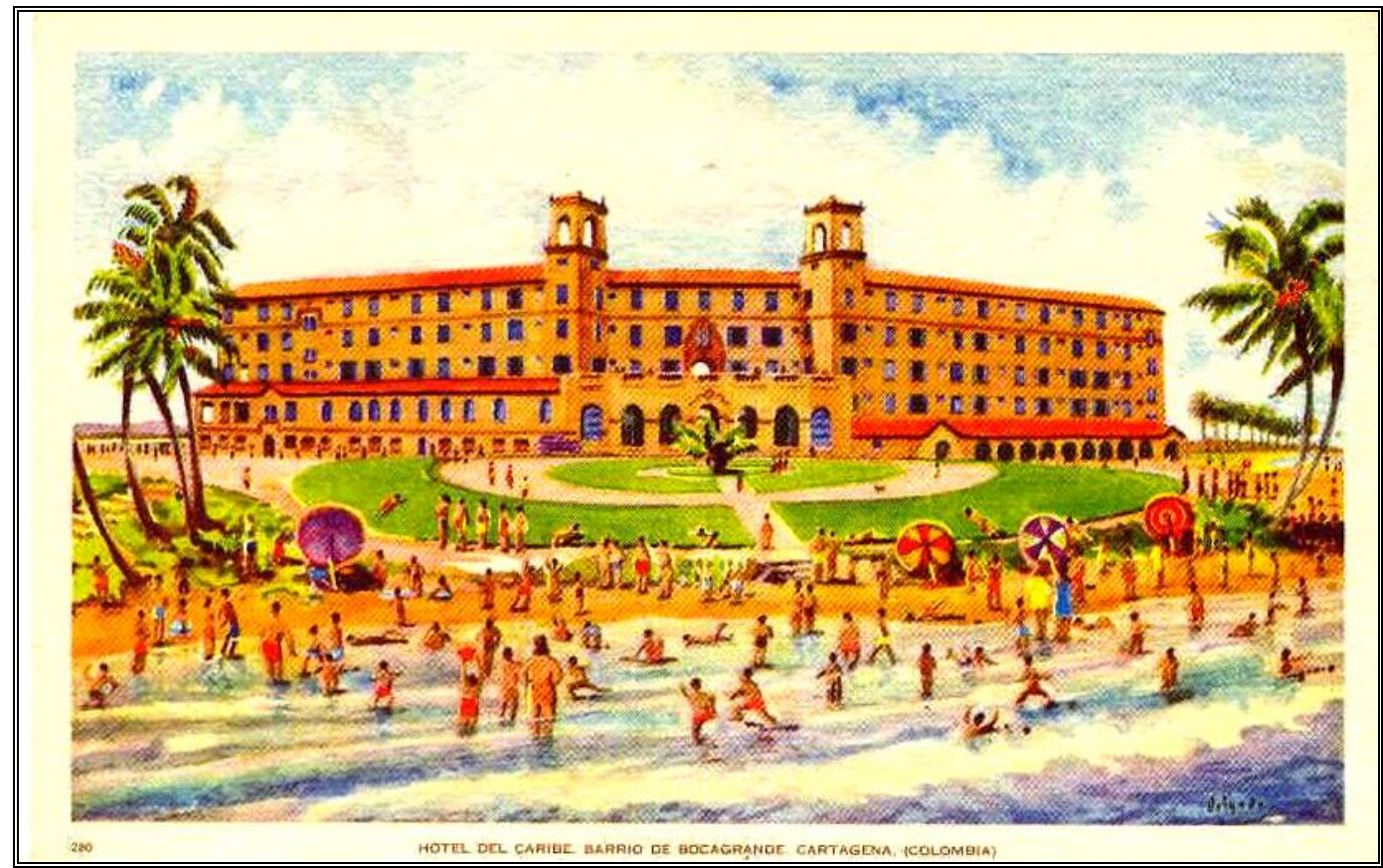

Imagen 2. Hotel Caribe de Cartagena

(Colección particular)

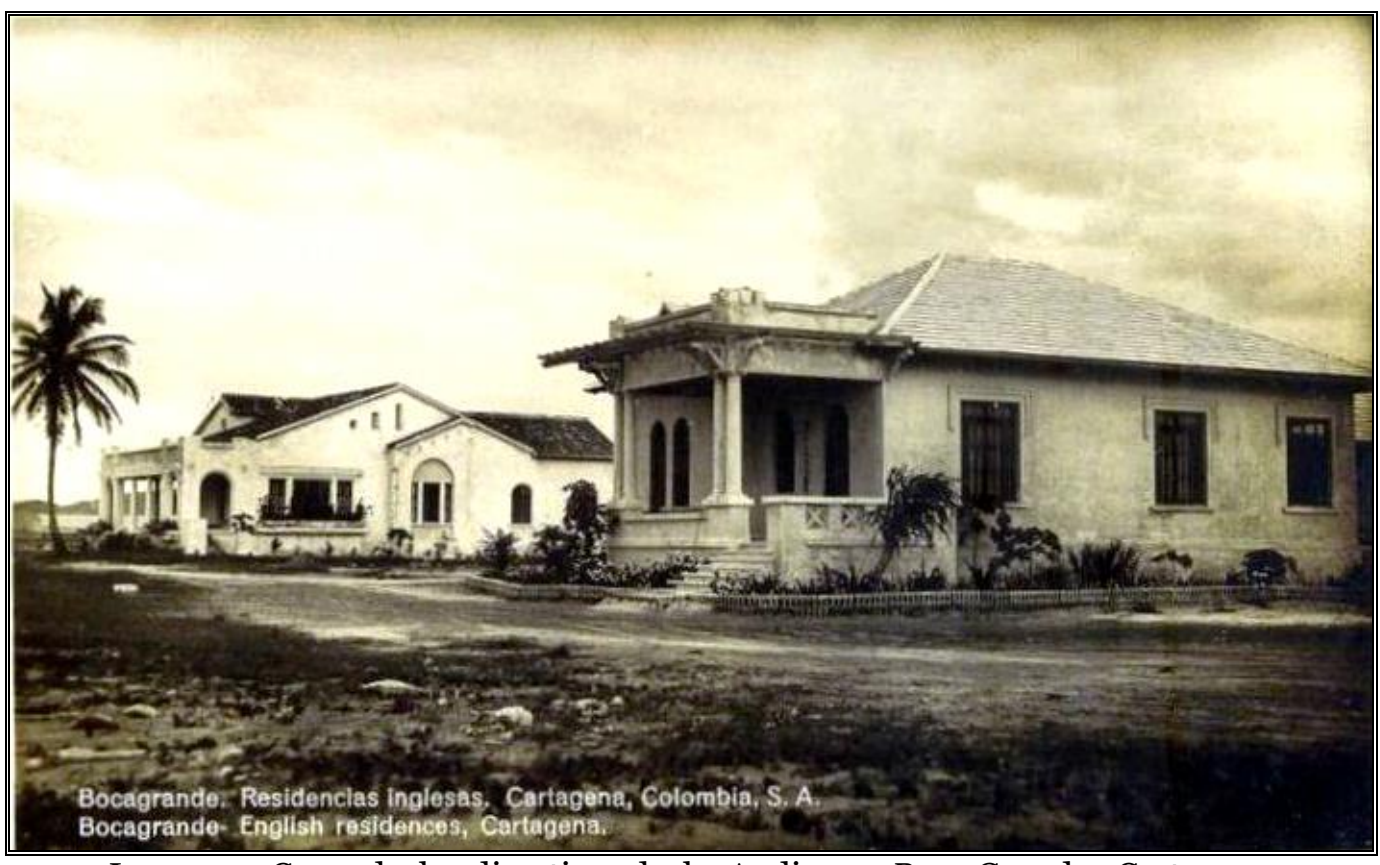

Imagen 3. Casas de los directivos de la Andian en Boca Grande, Cartagena (Colección particular) 


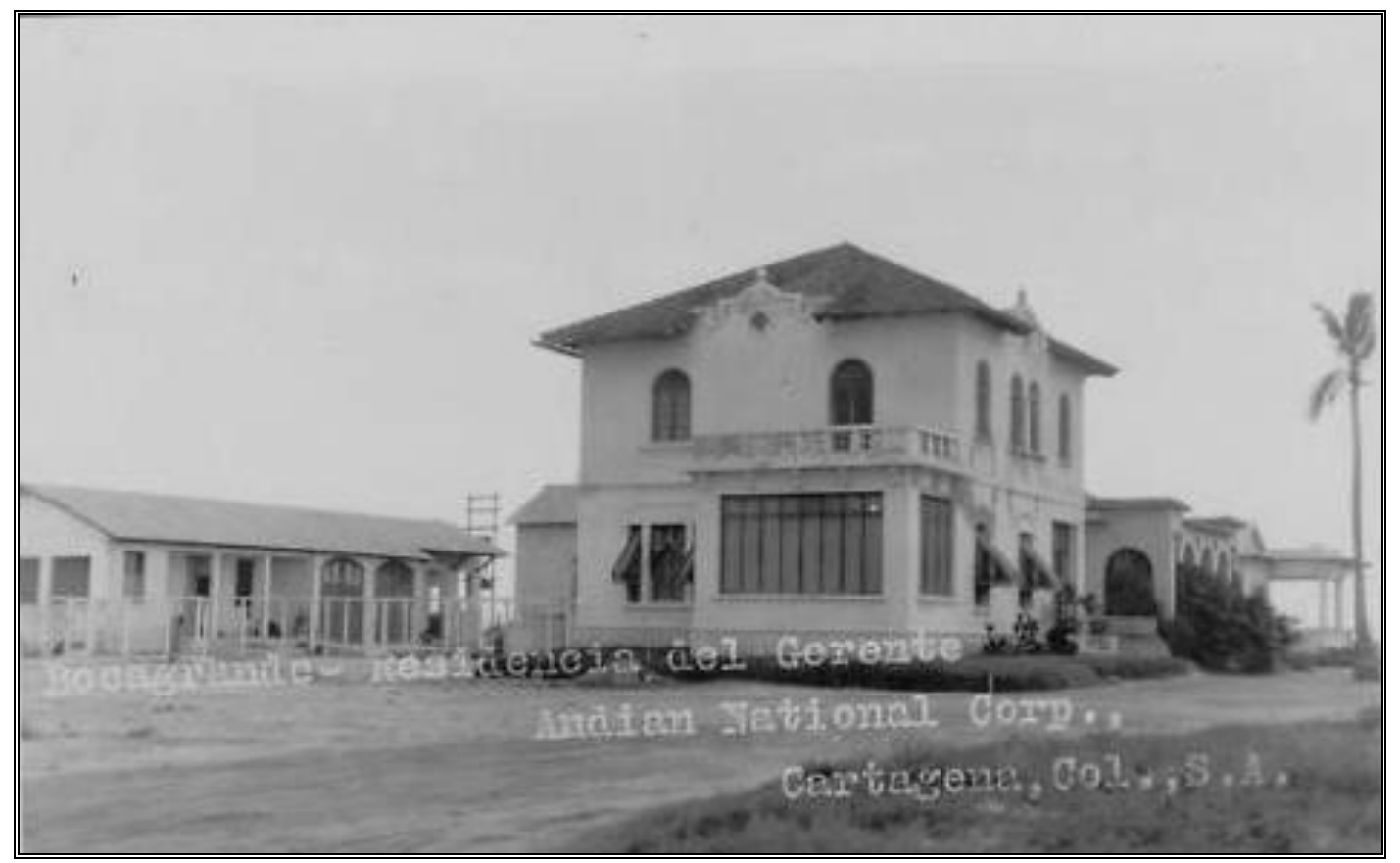

Imagen 4. Casas de los directivos de la Andian en Boca Grande, Cartagena (Colección particular)

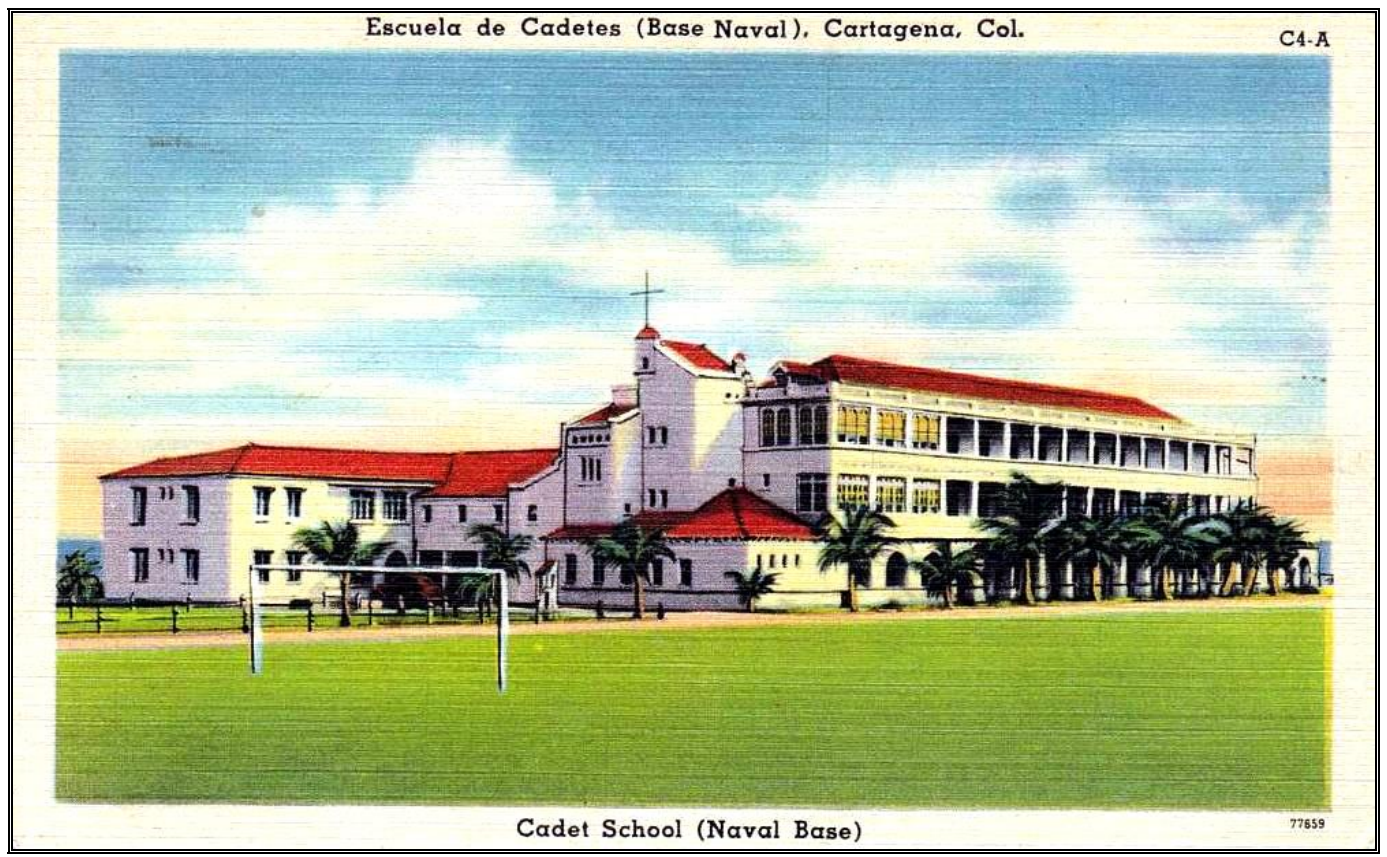

Imagen 5. Edificaciones de la Base Naval en Cartagena

(Colección particular) 
Aun cuando el Plano Regulador se inicia en 1948, desde mediados de esta década, se operan transformaciones que le iban imprimiendo a la ciudad un ritmo industrial y turístico que se alejaba del plan de ciudad portuaria como único eje de su actividad económica. En este orden podríamos citar que, en 1946, se fundó en el barrio de Boca Grande el moderno Hotel Caribe, guardando los estándares internacionales del momento, en cuanto a lo que a la prestación de este servicio se refiere, en el que funcionó el primer casino de la ciudad a partir de 1947 (imágenes $\mathrm{n} .{ }^{\circ} 1$ y 2). En el mismo año se pone en funcionamiento el aeropuerto de $\mathrm{Crespo}^{10} \mathrm{y}$ se crea el concurso nacional bianual de belleza. ${ }^{11}$ Estos primeros acontecimientos dejan ver la promoción que a la actividad turística se le quiere brindar en la ciudad. Los resultados de dichas acciones facilitarán la consolidación de Cartagena, en la segunda mitad del siglo Xx, como primer destino turístico a nivel nacional.

Sin embargo, este crecimiento fue progresivo. En los comienzos de la segunda mitad de ese siglo, el desarrollo del sector turístico en la ciudad no fue vertiginoso. Para cuando los registros existentes muestran un incremento marcado de tal actividad, la segunda mitad de siglo se encontraba bastante avanzada. ${ }^{12}$ No obstante es importante señalar que los mandatarios locales orientaban el diseño y los espacios de la ciudad en función de la actividad turística. Delineación que posteriormente posibilitaría una intensa actividad de ornato e infraestructura urbanística, de construcciones y servicios, para la zona de la ciudad en donde se desarrollaría tal empresa: los barrios de Boca Grande, Laguito, Castillo Grande y el centro amurallado, sectores que ostentarían el mayor grado de valorización territorial de la ciudad.

Encaminado a este propósito, el Plano de Ordenamiento de 1948, para el desarrollo turístico, sugería una delicada serie de modificaciones viales y la zonificación de los sectores que conforman la ciudad en: comerciales y residenciales.

\footnotetext{
${ }^{10}$ J. Báez y H. Calvo, "La economía de Cartagena en la segunda mitad del siglo xx: Diversificación y rezago", pp.72-73.

${ }^{11}$ AHC, Libro de Actas de los Anales del Concejo Municipal, "Acuerdo n. ${ }^{\circ}$, por el cual se fija a la ciudad de Cartagena como sede permanente del concurso de belleza que se celebrara cada año en las festividades del 11 de noviembre". Leído y puesto a discusión el articulo el H. C. Pareja modifica en el sentido que se efectué cada dos años. Cerrada la discusión es aprobado y adoptado el artículo con la modificación", Cartagena, 29 de febrero de 1948, p.2.

${ }^{12}$ J. Báez y H. Calvo, "La economía de Cartagena en la segunda mitad del siglo xx: Diversificación y rezago", p.94.
} 
Además de la validación de las edificaciones en: históricas, artísticas y ordinarias, para lograr la conservación total de la ciudad española colonial, las murallas, los fuertes y baluartes que la bordean, puesto que gracias a su atractiva arquitectura "se (puede) aprovechar su belleza y su interés histórico, como elementos comerciales valiosísimos". ${ }^{13}$ Así mismo, usufructuar las viejas construcciones y darles un uso moderno, tal como centro de servicios y entretención a los visitantes y, en este sentido panorámico de la ciudad vieja, adecuar los canales y lagunas internas de la urbe, para, entre otras cosas, "proporcionar un halago al visitante y al turista"; y como complemento del uso de los recursos naturales de la ciudad "crear también, en el sector de La Tenaza un balneario [...]".14

En el ambicioso plan vial, que generaría las soluciones adecuadas al problema de la movilidad actual, así como las del futuro, el Plano Regulador observaba lo siguiente: El Plano Regulador ha puesto especial esmero en que tanto la vías nuevas como las rectificaciones de las antiguas, formen un conjunto armónico que consulte las necesidades del futuro, y al mismo tiempo, vayan siendo practicables con los cursos de Cartagena, a medida que vaya progresando demográficamente y económicamente. ${ }^{15}$

Por tanto la transformación urbanística que se opera en este sentido responde a consideraciones modernizadoras, en cuanto a que se tiene en cuenta la proyección en los avances de los medios de transporte con el advenimiento del progreso económico de la ciudad y de sus habitantes. En aras de la funcionalidad, el Plano Regulador, planteó la necesidad de construir dos vías o avenidas centrales, que atraviesen la ciudad, aun cuando su recorrido por trechos sea paralelo, en lugar de una. Esto a razón de la topografía de la ciudad, los costos de la obra y el mayor descongestionamiento vehicular, que redundaría en más rapidez de desplazamiento.

Para tal objeto la "arteria troncal", (actual avenida Pedro de Heredia), que ha sido la columna vertebral del transporte terrestre de la ciudad, fue el eje vial del Plano Regulador. Se propendió por su ampliación y adecuación, como principal corredor de transporte de vehículos motores. La segunda "arteria vial" seria la actual avenida Pedro Romero, con la que se conformarían las dos troncales del trans-

\footnotetext{
${ }^{13}$ A. P., Memoria explicativa del Plano Regulador de José María González Concha, p.42r.

${ }^{14}$ A. P., Memoria explicativa del Plano Regulador de José María González Concha, p.56v.

15 A. P., Memoria explicativa del Plano Regulador de José María González Concha, p.28r.
} 
porte terrestre. En estas dos arterias deberían confluir todas las vías laterales, transversales, calles y avenidas pequeñas de la ciudad, tanto de ese momento, como en la ciudad futura. ${ }^{16}$ Se disponía, con éste plan vial, el desarrollo de otros proyectos de gran envergadura urbanística, que detallaremos más adelante.

Otros elementos importantes en la adecuación de vías se operarían en la ciudad colonial, como resultado de la zonificación de dicho sector. Éste debía estar conectado con la arteria troncal de la ciudad moderna. Para ello se decidió: ampliar las calles de la Media Luna y la Calle Larga, con el objeto de agilizar el tránsito en la zona de Getsemaní y; construir una avenida en la playa del Arsenal para dar salida al tráfico pesado de la plaza de mercado, ubicada en la bahía de Las Animas. ${ }^{17}$

El otro gran componente en materia vial que el Plano recomendaba era el Plan Acuático. Este plan debía conectar eficazmente las vías de tierra con los canales y lagunas de la ciudad, tanto por razones prácticas como de estilo, quedando expresamente registrado en las memorias de la siguiente manera: "En el plan vial acuático, como complemento del terrestre, [...], en el cual se ha dado especial atención a la continuidad y conexión con el plan vial terrestre, de modo que formen un conjunto perfectamente armónico". 18

Los objetivos que debía rendir este plan acuático, complementario, eran básicos pero necesarios. En cuanto a utillaje como caminos, los canales y lagunas debían servir cómo vías de transporte para pasajeros y carga, tanto en la zona urbana, como en el hinterland. Para ello debían convertirse en terminales viales importantes en las áreas de cargue y descargue, tanto en los centros de comercio "fuerte" como en el de comercio "al de tal". ${ }^{19}$

Así mismo, en procura de la higiene y la sanidad, los canales internos funcionarían como receptáculo de las aguas lluvias que por gravedad, gracias a las condiciones topográficas de la ciudad, finalizarían en estos, luego de ser transportadas por el alcantarillado superficial de la ciudad. De otro lado, las aguas "negras", producto del alcantarillado subterráneo, llegarían a los canales que las dispersarían

\footnotetext{
${ }^{16}$ A. P., Memoria explicativa del Plano Regulador de José María González Concha, pp.31r-32v.

${ }^{17}$ A. P., Memoria explicativa del Plano Regulador de José María González Concha, p.3or.

${ }^{18}$ A. P., Memoria explicativa del Plano Regulador de José María González Concha, p.32v.

19 A. P., Memoria explicativa del Plano Regulador de José María González Concha, p.32v.
} 
y evacuarían en la bahía exterior de la ciudad. ${ }^{20}$ Para alcanzar tales objetivos el Plan recomendaba "restablecer la normal comunicación entre la bahía, la laguna de la Virgen y el mar abierto, de manera que flujo y reflujo de las mareas establezcan una corriente continua que remueva las aguas y facilite, llegado el caso, la dispersión de las aguas negras" 21 para ello se necesitaba reabrir los antiguos canales de Chambacú, Bazurto, Matuna y Juan Angola, dando de esta manera fluidez y circulación al volumen líquido de los cuerpos internos de agua. ${ }^{22}$

Una última función, asignada al plan náutico, estaba relacionada con la estética urbana y el turismo. Todos los senderos navegables, canales y lagunas internas, debían contar con paseos peatonales y miradores, constituyéndose en zonas de atractivo turístico para propios y visitantes. ${ }^{23}$

Otro aspecto, de esta reestructuración urbana, en donde se fijó la mirada fue en el tema concerniente al ferrocarril. Para 1948 aún estaba en funcionamiento el ferrocarril Cartagena-Calamar, con su estación de llegada en el sector de La Matuna (imagen 6). Luego del incendio del muelle de La Machina, ubicado en la entrada de Boca Grande, la ubicación de la estación perdió su sentido y en consecuencia el Congreso de la República decretó, con la ley 62 de 1937, el traslado de la estación y el levantamiento de los rieles del centro de la ciudad ${ }^{24}$ para el mejoramiento del tránsito vehicular.

Cabe destacar que en Colombia existía el Consejo de Ferrocarriles, entidad encargada de todo lo concerniente a este asunto en el territorio nacional. Ésta institución sugería, para Cartagena, la construcción de la nueva estación en el barrio de Alcibia, aprovechando el lote de los talleres de la antigua estación. Sin embargo el Plano Regulador, en observancia de las necesidades que debía suplir la nueva edificación en cuanto a servir de Terminal para recibo de pasajeros, contar con amplitud suficiente para la zona de talleres de reparación de las locomotoras, depósitos y bodegas de mercancías, residencias para empleados y trabajadores del ferrocarril,

\footnotetext{
${ }^{20}$ A. P., Memoria explicativa del Plano Regulador de José María González Concha, p.32v.

${ }^{21}$ A.P., Memoria explicativa del Plano Regulador de José María González Concha, p.33r.

22 A.P., Memoria explicativa del Plano Regulador de José María González Concha, p.33r.

${ }^{23}$ A.P., Memoria explicativa del Plano Regulador de José María González Concha, p.34v.

${ }^{24}$ A.P., Memoria explicativa del Plano Regulador de José María González Concha, p.67r.
} 
así como zona de parqueaderos y patios para vehículos, encontraba inapropiado este barrio para tal propósito, máxime cuando el Consejo de Ferrocarriles planificaba que el Ferrocarril Troncal de Occidente hiciera su arribo en esta nueva Terminal, lo que multiplicaría el volumen de actividad en la estación ${ }^{25}$.

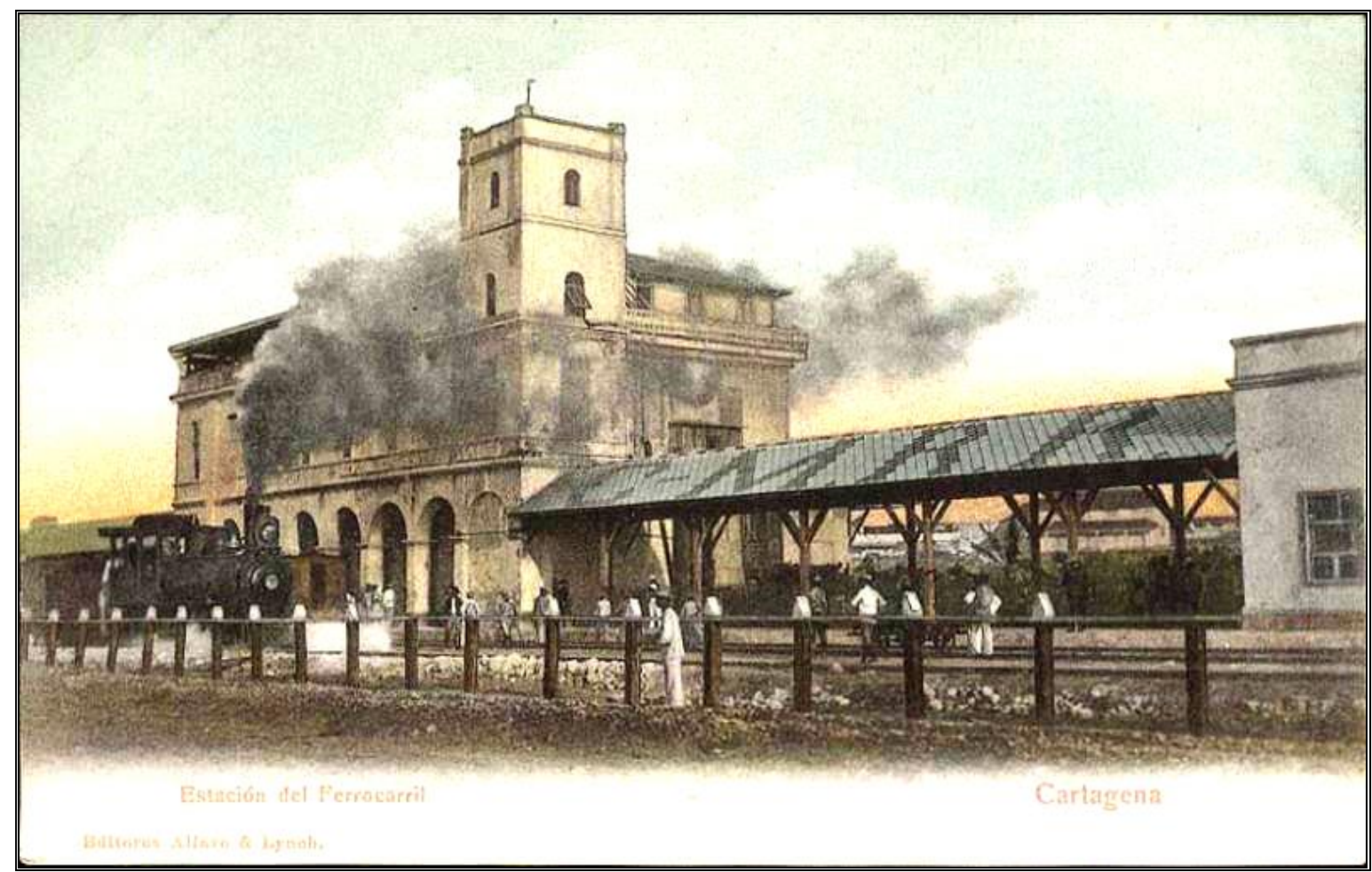

Imagen 6. Estación del ferrocarril Cartagena-Calamar, en el área de La Matuna, diagonal a la Torre del Reloj. (Colección particular)

${ }^{25}$ A. P., Memoria explicativa del Plano Regulador de José María González Concha, pp.68r-69v. 


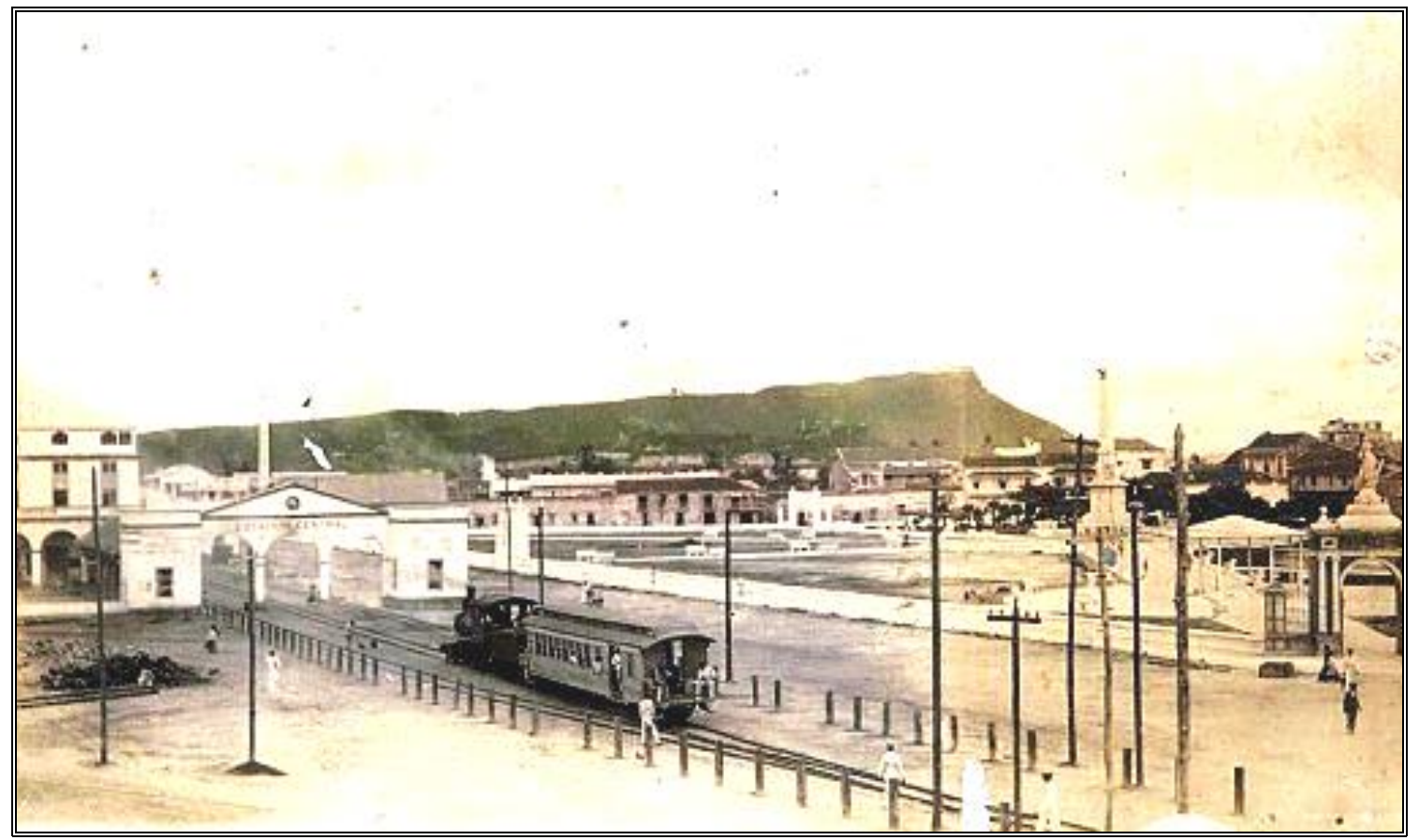

Imagen 7. Estación del ferrocarril Cartagena-Calamar, en el área de La Matuna.

(Colección particular)

Sin embargo existían cuatro razones de peso, argumentadas por el Plano Regulador, para no construir la estación en Alcibia. La primera argüía que dicho barrio se encontraba ubicado en el cuello de botella geográfico de la ciudad; la segunda, alegaba que era precisamente ese sector el corazón vial terrestre de la ciudad presente y futura, lo que, por un lado, limitaría en extremo el espacio territorial de operaciones de la estación, y por otro, la constituiría en un nudo infranqueable en las vías troncales de la ciudad. Como solución a este impase el Plano Regulador recomendaba, como un mejor lugar, el semi-despoblado barrio del Bosque, cuyos terrenos resultarían baratos, por ser del distrito, a la hora de adquirirlos. Además la zona del barrio propuesto poseía un área mucho mayor que Alcibia, colindante con la bahía natural interna de la ciudad, asimismo se hallaba cerca del nuevo Terminal marítimo de Manga, lo que facilitaría el trasbordo, cargue y descargue de mercancías por esta vía. Una tercera razón de fondo que alegaba el Plano, era la cercanía del Bosque con el centro de la ciudad, lugar donde funcionaban el comercio fuerte, la plaza de mercado y el comercio fino, con lo que se abarataban los costos de construcción de vías carreteables para acceso al sector. Por último, en los presupuestos de zonificación, el Bosque estaba pensado como zona de desarrollo indus- 
trial de la ciudad, por lo que la ubicación de la estación de ferrocarriles en este barrio resultaba pertinente. ${ }^{26}$ Para que se ejecutaran los cambios en la obra, se enviaron comisiones a la ciudad de Bogotá, ante el Ministerio de Obras Publicas y el Consejo Nacional de Ferrocarriles, entre los meses de abril de 1947 y marzo de 1948, quedando finalmente aprobadas las recomendaciones generales del Plano. ${ }^{27}$

En materia de prestación de servicios comerciales el Plano observaba tres modalidades a desarrollarse en la ciudad. Comercio Fuerte: que debía realizarse entre mayoristas y proveedores e implicaba la utilización de medios de transporte pesado, tanto terrestres como navieros. Comercio Fino: referido a los artículos de lencería, perfumería y demás elementos de ornato personal y lujos. Por último, el denominado Comercio al detal: que obedece a las ventas directas de víveres y bienes de consumo entre el vendedor minoritario y el comprador-consumidor. Estas tres variantes de la actividad comercial implicarán, en materia urbanística, igual número de medidas de planeación, organización y distribución de las zonas en que se desarrollarán.

Para mediados del siglo xx, fecha en que comienza a operar el Plano Regulador, la ciudad de Cartagena cuenta con una sola plaza de abastos al mayoreo. El Mercado Popular (imágenes ${ }^{\circ}{ }^{\circ} 7,8,9$ y 10), estaba ubicado entre la bahía de las Ánimas y el barrio de Getsemaní, y ofrecía, amén de su función principal que consistía en surtir de vituallas procedentes del hinterland a la mayoría de los habitantes de la ciudad, productos artesanales, carnes y pescados. Proporcionaba, también, a sus visitantes y trabajadores, sitios de comidas y bebidas alcohólicas, situación que en más de una ocasión generó controversia sobre la conveniencia de la ubicación del mercado en ese sitio. ${ }^{28}$ Por otra parte, gracias a su cercanía con el muelle de La Machina, el mercado servía como bodega de almacenamiento de muchas de las mercancías que ingresaban por este puerto a la ciudad, lo que sumaba un número significativo de trabajadores del puerto a las jornadas de "desordenado" esparcimiento.

\footnotetext{
${ }^{26}$ A. P., Memoria explicativa del Plano Regulador de José María González Concha, pp.71r-72v.

${ }^{27}$ A. P., Memoria explicativa del Plano Regulador de José María González Concha, p.74v.

${ }^{28}$ A. P., Memoria explicativa del Plano Regulador de José María González Concha, p.65r.
} 


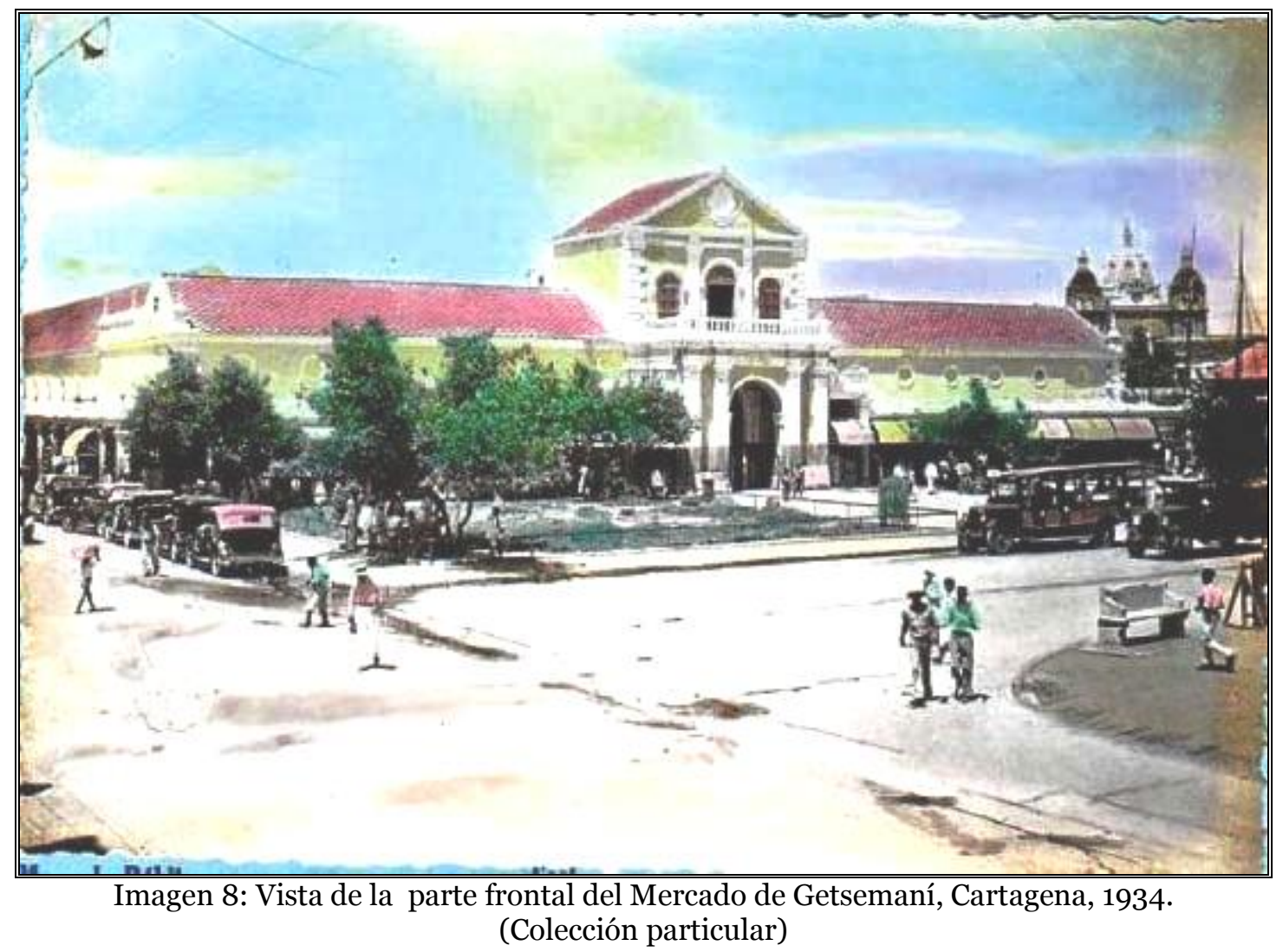

No obstante, el Plano Regulador, consideró pertinente la permanencia del mercado en este sitio, puesto que se hallaba cerca de la zona mayormente poblada, contaba con vías de acceso y salidas, terrestres y marítimas rápidas, lo que facilitaba enormemente el cargue y descargue de mercancías en su área, labor que por demás no interfería con el tráfico del resto de la ciudad. Sin embargo, consideraban los ingenieros del Plano, que debían realizarse algunas mejoras al interior de los edificios del área administrativa, el saneamiento de su lote, la higienización de sus locales y la prohibición de algunas de las prácticas "controversiales" que en él se realizaban. ${ }^{29}$

\footnotetext{
29 "El plano Regulador ha optado por la conservación de la plaza actual, de Cartagena, después de pesar las consideraciones generales anteriores, y en vista de que su ubicación es la más apropiada para surtir de víveres a un gran sector, (...)”, A.P., Memoria explicativa del Plano Regulador de José María González Concha, pp.65v.-67r.
} 


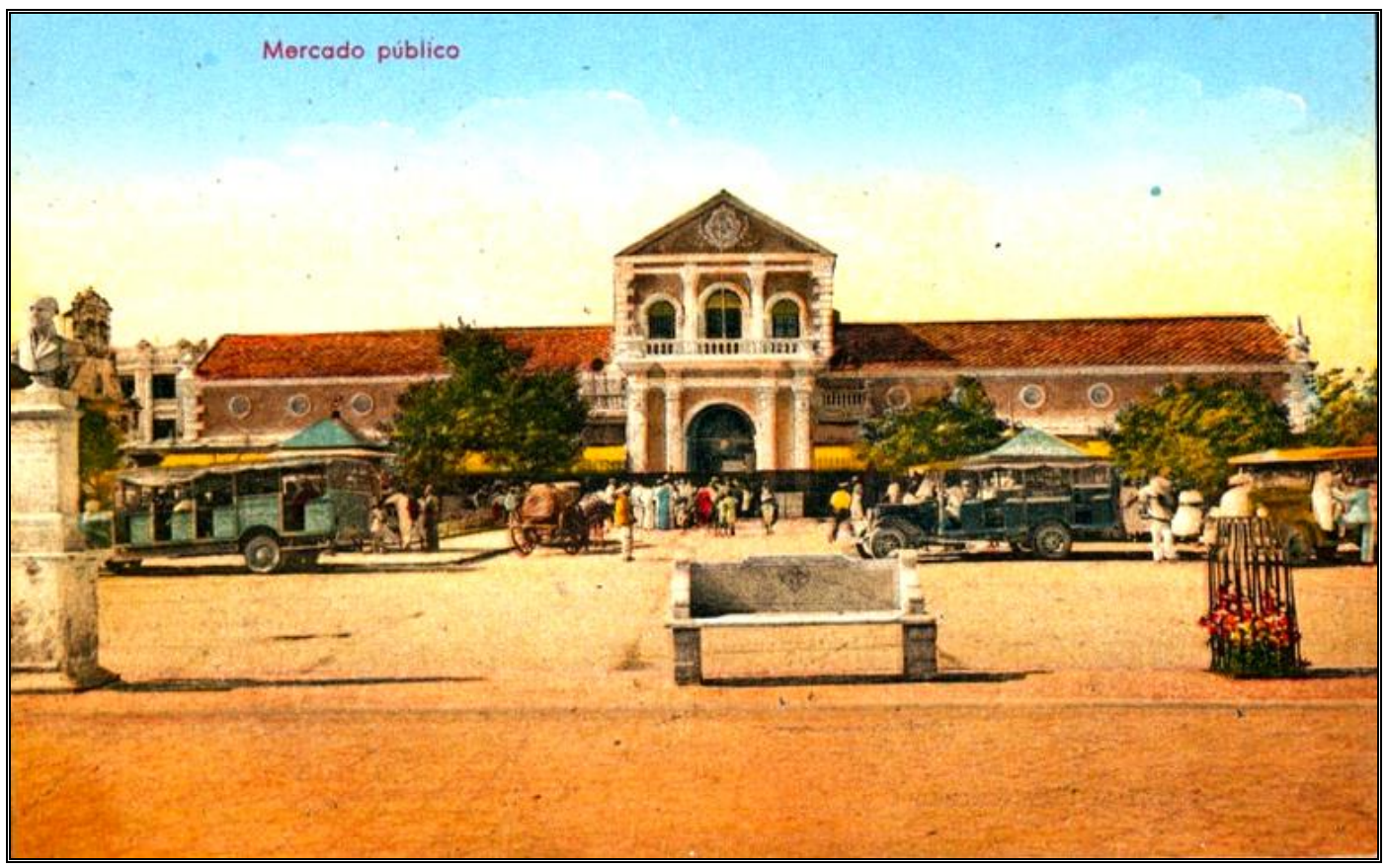

Imagen 9: Vista de la parte frontal del Mercado de Getsemaní, Cartagena, sf. (Colección particular)

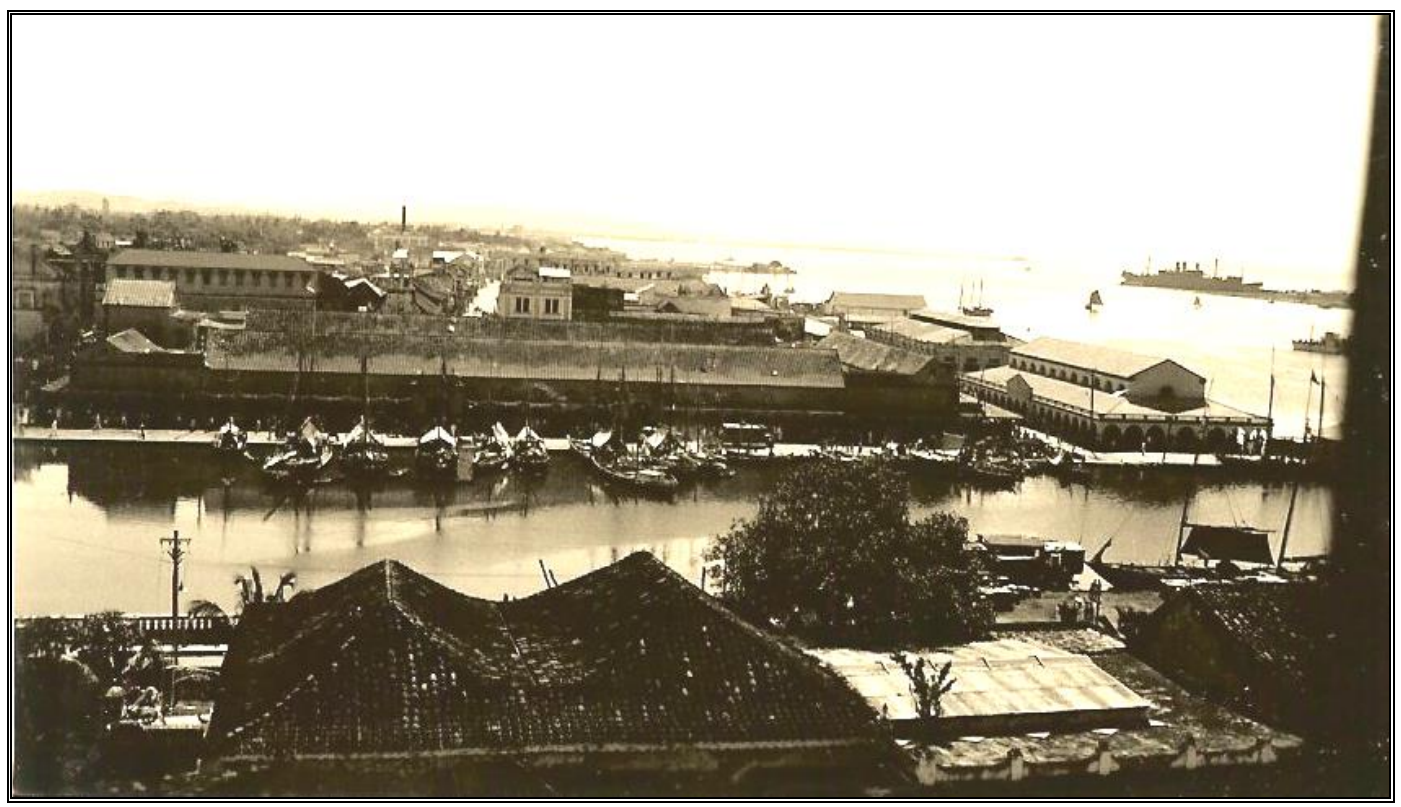

Imagen10: vista del Mercado de Getsemaní, área de atraque de embarcaciones menores, sf. (Colección particular) 


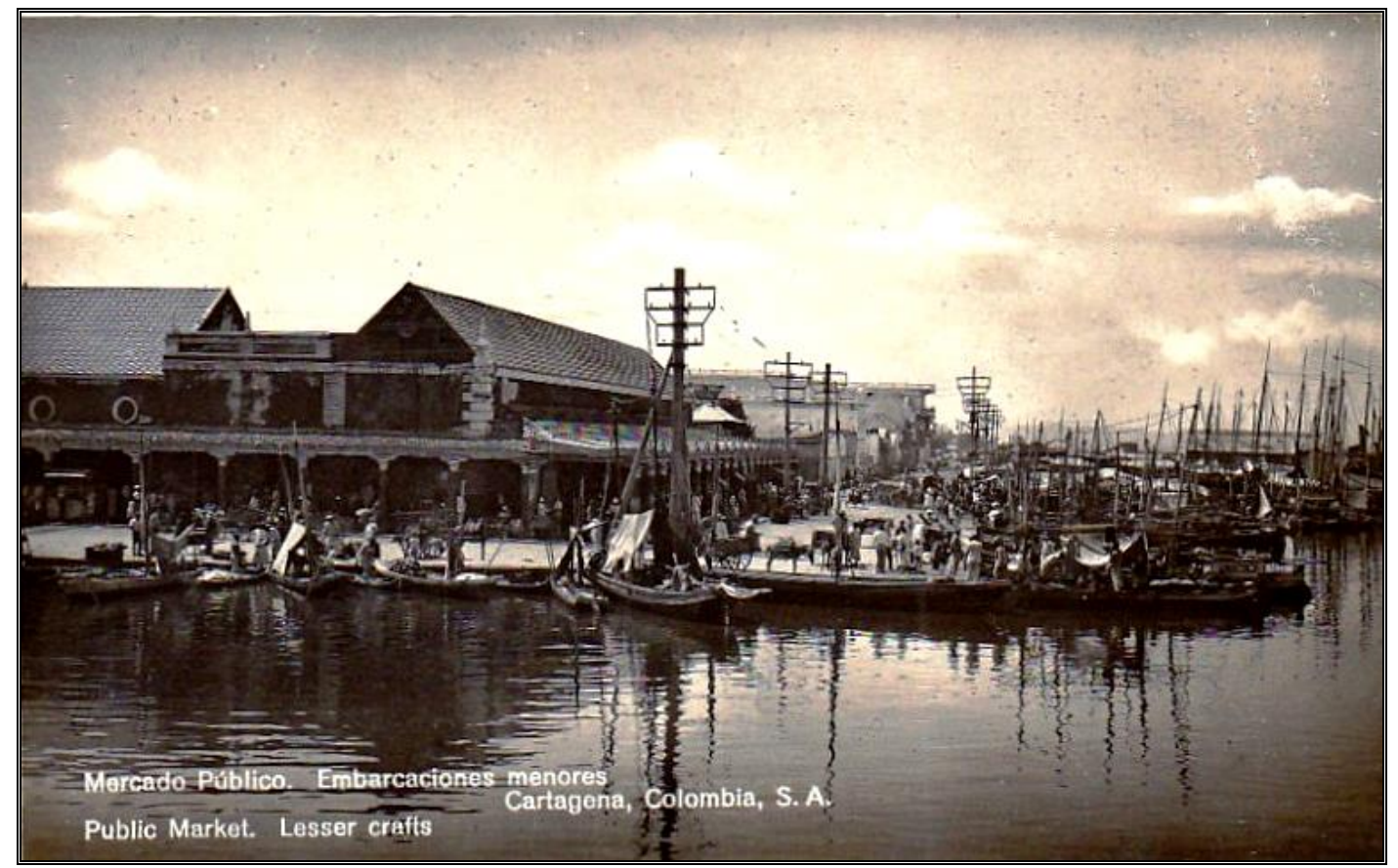

Imagen 11: Mercado de Getsemaní, área de atraque de embarcaciones menores, sf. (Colección particular)

En la ciudad colonial, zona de mayor concentración de personas, debía construirse lo que se denominó el Centro Cívico Comercial. A éste le correspondía servir como área de desarrollo de la actividad comercial fuerte, llevada a cabo por las casas comerciales de ventas al mayoreo, que utilizaban transporte pesado y movimiento voluminoso de mercancías. Funcionarían, también en este Centro, los edificios administrativos del distrito y del departamento, tales como el de la gobernación, lo mismo que algunos de los edificios administrativos de ciertas industrias que funcionaban en Mamonal, así como las oficinas de los bancos que en la ciudad realizaban su actividad. 30

Su ubicación, respetando los valores de conservación del patrimonio y de zonificación del Plano, anteriormente expuestos, debía ser en el campo de la Matuna. Este sector, por encontrarse fuera del recinto amurallado y por presentar un acceso rápido a las avenidas de la ciudad antigua que se comunicaban con las arte-

${ }^{30}$ A. P., Memoria explicativa del Plano Regulador de José María González Concha, p.51r. 
rias troncales de la ciudad, permitiría un flujo vehicular rápido y eficaz que no obstruyera el tráfico lento del sector amurallado en sí31 (imagen 12).

Este Centro Cívico Comercial le permitiría a la ciudad, a través del Plano Regulador, mostrar una cara moderna en cuanto al urbanismo se refiere. Estaba destinado a ser integrado, en su conjunto, por rascacielos y edificaciones de vanguardia. ${ }^{32}$ Además, su ubicación por fuera del cordón de murallas, que delimita los barrios de arquitectura colonial, no rompe la armonía del paisaje urbano, ni va en detrimento de las leyes, normas y decretos de conservación del patrimonio. ${ }^{33}$

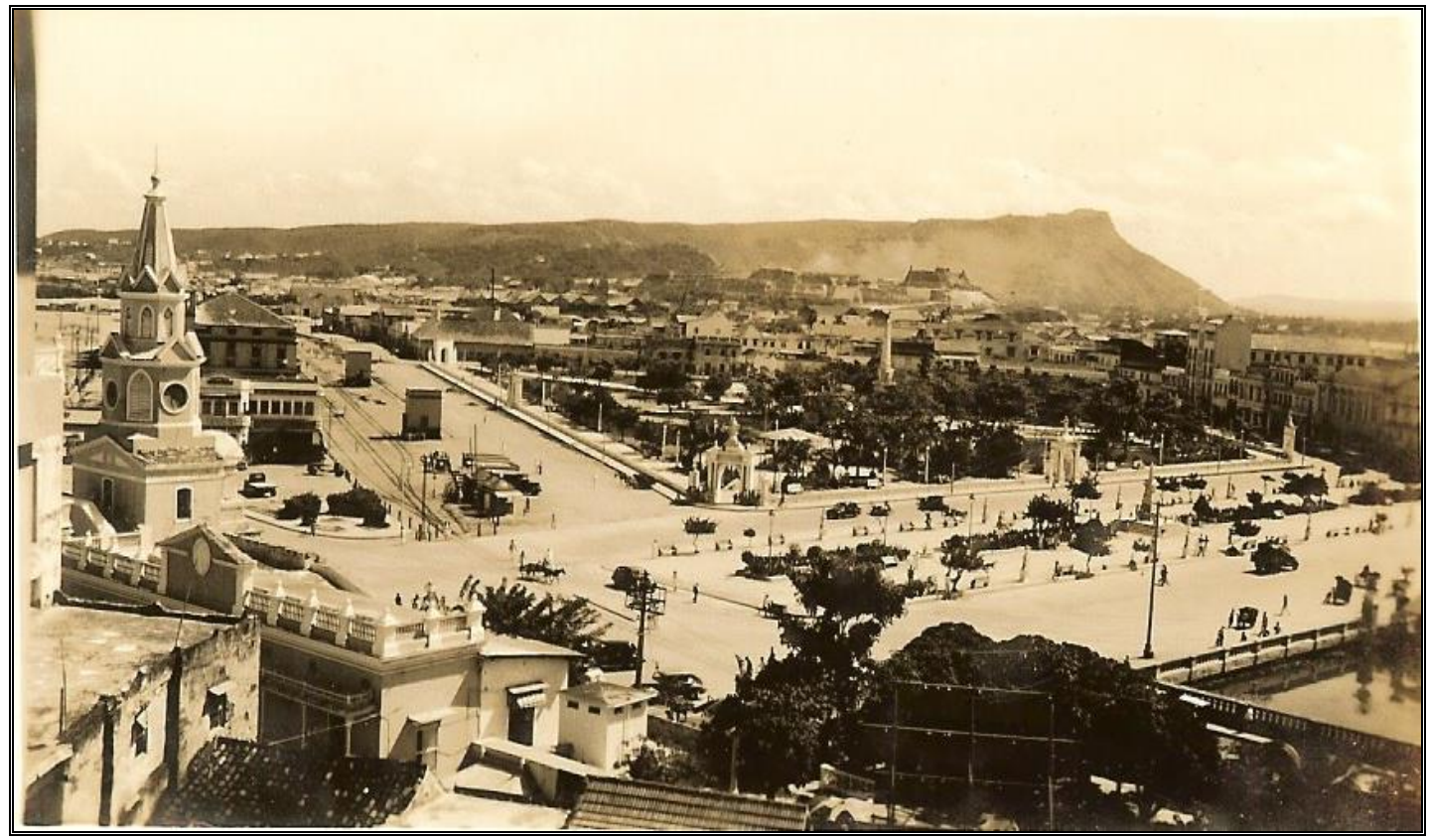

Imagen 12. Panorámica del Campo de la Matuna, antes de su urbanización, contando solo con la estación del ferrocarril. (Colección particular).

${ }^{31}$ A. P., Memoria explicativa del Plano Regulador de José María González Concha, p.62v.

32 "En los años 40 y 50, se dan los inicios de la arquitectura de transición en la Cartagena del siglo $\mathrm{XX}$, esta estaba constituida por edificaciones de carácter moderno, inspiradas en las construcciones californianas y europeas del lado del mediterráneo". Lorenzo Fonseca y Alberto Saldarriaga, "Aspectos de la arquitectura colombiana del siglo Xx", en Carlos Castillo (comp.), Urbanismo y vida urbana, Instituto colombiano de cultura, Bogotá, 1977, pp.158-159.

${ }^{33}$ A. P., Memoria explicativa del Plano Regulador de José María González Concha, p.62v. 
Para el comercio fino, explicado anteriormente, la estrategia del Plano Regulador era desarrollarlo en la zona histórica de la ciudad. Debido a que su actividad no implicaba el movimiento de transporte pesado, ni permanente, que pudiera generar traumatismos en el tránsito de las calles de la ciudad de las murallas, ni alteraciones en la vida residencial de este sector. Las recomendaciones consistían en realizar pequeñas modificaciones en algunas casas coloniales del centro antiguo, ya que tal actividad comercial no riñe ni con la estructura, ni con el diseño de estos inmuebles y más bien contribuye a la conservación del patrimonio arquitectónico de la ciudad. ${ }^{34}$ De ésta manera se generaría una dinámica comercial atrayente para los residentes y visitantes de la ciudad. El movimiento mercantil promueve la creación de locales para el sano esparcimiento y la conversación, lo que, supuestamente, invitaría al viajante y al natural a visitar reiteradamente dicha zona.

Continuando con las obras urbanísticas civiles, en la parte que hace referencia al sector salud y hospitalario el Plano Regulador, luego de un estudio y consultas con profesionales de la situación hospitalaria de la ciudad, concluía que "No existen estadísticas que puedan servir de base para un estudio exacto de los problemas relacionados con hospitales.- De los datos que se obtuvieron se puede deducir que las enfermedades predominantes en el Dpto.- de Bolívar son: El paludismo, la parasitosis intestinal y la tuberculosis". ${ }^{35}$ Para el año en que se realizó dicho estudio existía en la ciudad un solo hospital, Santa Clara, que, según el concepto del Plano, no poseía las condiciones modernas ni capacidad de atención de las necesidades de ese momento para las enfermedades generales. En consecuencia, se recomendaba la mejora y ampliación de éste centro, mientras se realizaba la construcción de varios hospitales (menores) en los diferentes sectores de la ciudad y no un único hospital general. ${ }^{36} \mathrm{El}$ Plano recomendó, entonces, construir una agrupación de hospitales y servicios médicos especializados, así como una clínica de auxilio a los tuberculosos, anexa a estos hospitales, en la localidad de Zaragocilla. ${ }^{37}$

\footnotetext{
${ }^{34}$ A. P., Memoria explicativa del Plano Regulador de José María González Concha, p.63r.

35 A. P., Memoria explicativa del Plano Regulador de José María González Concha, p.75r.

${ }^{36}$ A. P., Memoria explicativa del Plano Regulador de José María González Concha, p.75r.

${ }^{37}$ A. P., Memoria explicativa del Plano Regulador de José María González Concha, p.75r.
} 
Para la época existía en Cartagena un único campo santo, el Cementerio de Manga. Frente a éste el Plano Regulador anotaba que, por estar ubicado en un barrio residencial de la zona céntrica de la ciudad, "entorpecía” la expansión urbanística; agregaba que el terreno ocupado era pequeño y el lote que recientemente se había adquirido para su ampliación era insuficiente. Por último, se concluía que, el terreno donde funcionaba, por su humedad "no permite la pronta descomposición de los cadáveres", lo que hace que los cuerpos permanezcan largos años en perfecto estado de conservación. Con base en estas observaciones el Plano recomienda clausurar el cementerio de Manga. Insiste en conservarlo como recinto sagrado de osamentas, cercar su área con muros altos para aislarlo del entorno y construir una capilla, en el nuevo lote, para embellecer la localidad. En contraprestación se propone construir un nuevo Campo Santo en el barrio de Amberes, en un lugar amplio, seco y elevado. ${ }^{38}$ Otra recomendación que tributaría a la consolidación de Manga, como zona netamente residencial, fue la de trasladar la planta eléctrica ubicada a la entrada del barrio hacía la zona industrial del Bosque. ${ }^{39}$

Un capítulo aparte del plano Regulador es el que hace referencia al sector educativo de la ciudad. Las observaciones del Plano dividen a los centros educativos en cinco niveles, definidos así: Escuelas primarias, colegios de bachillerato, escuelas profesionales, universidad e ingeniería hidráulica. Las conclusiones planteadas para las escuelas primarias surgen de un debate sobre la conveniencia y pertinencia de realizar concentraciones educativas y/o propugnar por escuelas "diseminadas". Luego de sopesar valoraciones como el desplazamiento de los niños, el entorno favorable a la complementariedad de la educación (escuela/entorno familiar) y el coste del distrito en el sostenimiento de las escuelas; el Plano Regulador concluyó:

Las escuelas no deben estar concentradas en los centros vitales de la ciudad, sino, que deben estar localizadas en los diversos barrios,- procurando que su situación facilite lo más posible la asistencia de los escolares y que gocen allí de la tranquilidad que no pueden darle los barrios fabriles o comerciales.- Quedo,

${ }^{38}$ A. P., Memoria explicativa del Plano Regulador de José María González Concha, p.76r.

${ }^{39}$ A. P., Memoria explicativa del Plano Regulador de José María González Concha, p.76r. 
pues, excluido del proyecto del Plano Regulador, toda concentración escolar de primera enseñanza. ${ }^{40}$

En lo que tiene que ver con las instituciones educativas para bachillerato, el Plano Regulador, luego de examinar las características del personal que asiste a estos centros de formación, en tanto que no son personas autónomas pero tampoco niños que requieran un cuidado inmediato de sus padres, propone que cualquiera de ambos sistemas podría ser funcional, bien sean las concentraciones y/o los centros diseminados. Para el caso de los centros de formación media las recomendaciones no serían las mismas. En observancia que los colegios de primaria y la universidad son costeados por el estado, mientras que los centros de formación media se sustentan en un modelo de economía mixta, no se podría, por parte del proyecto, someter su ubicación a zonas de concentración, sino, más bien todo lo contrario. Eso sí, los sitios deben escogerse entre los más tranquilos, pero con fácil acceso a las arterias de distribución. 41

En lo referente a las escuelas profesionales, (aquellas que dictan carreras profesionales, pero, que no están ligadas directamente con la universidad), como son generalmente de iniciativa privada "[...] estos planteles deben formar parte integrante de las zonas residenciales, comerciales y aun ferroviarias [...]".42 En el terreno urbanístico, el Plano argumentaba que:

Esta tendencia, que puede llamarse "descentralizadora”, del Plano Regulador, es lógica si se le aplica a cualquier ciudad de Colombia, pero en Cartagena es algo más que lógica, es necesaria, dado el carácter poli céntrico de la ciudad, el cual aconseja que cada sector tenga una organización propia, ligada naturalmente a la organización general de la ciudad. ${ }^{43}$

Los edificios de la Universidad de Bolívar, luego de consultar con el entonces profesor de la Universidad Nacional Luís López de Meza, quien en el ámbito nacional recomendaba los diseños funcionales de los campus de las universidades sec-

\footnotetext{
${ }^{40}$ A. P., Memoria explicativa del Plano Regulador de José María González Concha, p.8or.

${ }^{41}$ A. P., Memoria explicativa del Plano Regulador de José María González Concha, p.8or.

${ }^{42}$ A .P., Memoria explicativa del Plano Regulador de José María González Concha, p.82v.

${ }^{43}$ A. P., Memoria explicativa del Plano Regulador de José María González Concha, p.82v.
} 
cionales, ${ }^{44}$ se planificó construirlos en una zona por fuera de la ciudad amurallada. Esto en previsión de la amplitud territorial que debía tener la institución para su buen funcionamiento. La zona amurallada, por lo tanto, no era recomendable y en consecuencia se fijó "el extremo noreste de la ciénaga de Tesca como el lugar más apropiado para el desarrollo de una amplia Universidad". 45

De otra parte el Plano Regulador en su proyección de ciudad poli funcional dedicaba un aparte a la Base Naval Militar, que operaba en Cartagena. Con relación a la misma se señalaba su futuro, su traslado, su re-localización en el mediano plazo y su planificación. Lo mismo que lo concerniente al Hospital Naval Militar. ${ }^{46} \mathrm{La}$ Base se encontraba ubicada en un sector que, dentro de los parámetros del Plano Regulador, estaba destinado a una zona exclusivamente residencial. Para dirimir las diferencias que podían existir entre civiles y militares se creó una junta compuesta por expertos navales y los arquitectos que desarrollaban el Plano. El fin era determinar la futura ubicación de este complejo militar. ${ }^{47}$ Algunas de las razones que argumentaba el Plano para el traslado de la Base eran, por una parte, que los terrenos en los que se encontraba limitaban el espacio operativo de ésta, y por otro lado, que estos terrenos de reciente formación presentaban un nivel estructural diseñado para resistir exclusivamente la infraestructura civil residencial y la Base necesitaba edificaciones de carácter militar y administrativo mucho mas robustas y amplias. $^{48}$

El traslado de la Base Naval era, pues, pertinente, y su nueva ubicación debía pensarse no solo para su funcionamiento en este periodo, sino también, para su futuro. La Dirección de Marina había realizado sugerencias sobre el nuevo terreno de funcionamiento de la Base. La primera de estas recomendaciones era La isla de Tierra Bomba (Ley 90 de 1943). Lo que implicaba trasladar el leprosorio que allí se encontraba. La isla contaba con beneficios como: La solides del suelo, una bahía natural y amplitud en sus terrenos; pero presentaba inconvenientes tan insalvables en ese momento, como la enorme inversión económica a realizar en la adecuación

\footnotetext{
${ }^{44}$ A. P., Memoria explicativa del Plano Regulador de José María González Concha, p.82v.

${ }^{45}$ A. P., Memoria explicativa del Plano Regulador de José María González Concha, p.82v.

${ }^{46}$ A. P., Memoria explicativa del Plano Regulador de José María González Concha, p.83r.

${ }^{47}$ A. P., Memoria explicativa del Plano Regulador de José María González Concha, p.83r.

48 A. P., Memoria explicativa del Plano Regulador de José María González Concha, pp.84v-85r.
} 
de servicios como acueducto, alcantarillado y electricidad, por lo que el Plano desechó de momento este sitio. Otra zona recomendada fue Pasacaballos, en el extremo sur de la bahía, entre el Country Club y la desembocadura del Canal del Dique, por su fácil conectividad con la ciudad y con el resto del país; además de la factible adecuación de servicios y la amplitud de sus terrenos, sin embargo, como parte de estos terrenos pertenecen a la Andian National Corporation, la compra de ellos resultaba, en ese momento, poco posible. ${ }^{49}$

En conclusión el Plano Regulador de 1948 aconsejaba, por el momento, adecuar la urbanística exterior de la Base en su actual ubicación para que no riñera con el paisaje urbano y de zonificación que el Plano había trazado. Recomendó, realizar en su interior, las reformas arquitectónicas necesarias, por personal calificado, para acabar con su caótica distribución. De todas maneras no descartó, para un futuro, el traslado de la misma, cuando las condiciones económicas de Cartagena lo permitieran. ${ }^{50}$

En cuanto al Hospital Militar, que funcionaba en el actual Museo Naval, el Plano Regulador recomendaba su traslado definitivo. Sin embargo propuso ensanchar y ampliar, por el momento, el actual. Se barajaban en ese entonces dos posibilidades: La de construir el edifico del hospital ligado a la Base, y la de su construcción fuera de ella. Las ventajas de construirlo adosado a la Base se resumen en las de su administración; y las de construirlo fuera del perímetro de ésta, apuntaban a su integración a la vida civil de la ciudad, así como la de utilizar un lote de propiedad de la nación y no tener que esperar a que la Base encontrara su terreno; ${ }^{51} \mathrm{fi}$ nalmente se optó por la segunda iniciativa y el Hospital Naval quedó ubicado en su actual sitio a la entrada del barrio de Boca Grande.

\section{De la necesidad de diversificar a la exclusión}

Si bien la ciudad, su elite, acogió la mayoría de las recomendaciones efectuadas por los ingenieros y arquitectos del Plano Regulador, los cambios y transformaciones

\footnotetext{
${ }^{49}$ A. P., Memoria explicativa del Plano Regulador de José María González Concha, pp.85r.-85v.

${ }^{50}$ A. P., Memoria explicativa del Plano Regulador de José María González Concha, p.86r.

${ }^{51}$ A. P., Memoria explicativa del Plano Regulador de José María González Concha, p.88v.
} 
aplicados al funcionamiento de la ciudad, como espacio habitacional, social, de desarrollo y progreso de la totalidad de sus habitantes, no funcionaron. Ineficacia que se explica por la ausencia de una política urbana incluyente en la ciudad que facilitara el acceso de los habitantes de los "barrios pobres" al disfrute de servicios domiciliarios básicos, a una adecuada atención de sus necesidades en materia de salud y a su vinculación formal con el sector productivo por medio de una educación con la cobertura y calidad requerida en el mercado laboral del momento. Lo que se observa, entonces, es que la localización de las obras de renovación y equipamiento en ciertos sectores de la ciudad, recomendadas por el Plano regulador, densificó el paisaje de la exclusión social.

Exclusión social que, como lo plantea Manuel Hernández Pedreño, se explaya en la ciudad de forma multidimensional y multifactorial. Marginación que en su extenso significado abarca, incluso, a la categoría de pobreza. Dando cuenta de "un proceso que afecta de forma diferente a cada individuo, dependiendo de su potencial individual y del contexto social". 52

Desde esta perspectiva, Hernández Pedreño, considera que son seis los rasgos que caracterizan al concepto de exclusión social: 1) es un fenómeno estructural; 2) es un concepto dinámico; 3) es una realidad multifactorial y multidimensional; 4) es una experiencia heterogénea; 5) es una situación abordable desde las políticas públicas y; 6) posee un factor subjetivo/individual. 53

Como fenómeno estructural es el resultado de una determinada estructura social, política, económica y cultural. Por lo tanto la exclusión social es relativa, dependiendo su contenido social de los significados espaciales y temporales que se le asignen; su carácter de noción dinámica se explica porque es un conjunto procesos, más que una situación estable, afectando de forma cambiante a grupos y personas en función de su ecuación de vulnerabilidad respecto a las dinámicas sociales de riesgo y marginación.

Como realidad multifactorial la exclusión social puede explicarse por factores como el desempleo, la pobreza severa, la falta de asistencia en servicios educativo y de salud, precariedad laboral, aislamiento relacional y dificultades económi-

\footnotetext{
${ }_{52}$ Manuel Hernández Pedreño, Exclusión social y desigualdad, Murcia, Universidad de Murcia, 2008, p.16.

${ }^{53}$ M. Hernández P., Exclusión social y desigualdad, pp.38-39
} 
cas en el hogar por lo que las dimensiones de esta realidad son de naturaleza laboral, económica, cultural, personal y social; de lo anterior se deriva que la exclusión social sea un proceso muy heterogéneo que afecta a muchos y muy diversos grupos; puesto que es un fenómeno estructural, la exclusión social, es posible abordarlo de forma estratégica, a través de políticas efectivas que promuevan las práctica de inclusión, ya que en muchos casos es producto de políticas ineficaces.

Por último, no se puede dejar de lado ciertos factores individuales relacionados con la subjetividad y la atribución de sentido a la propia situación de precariedad, vulnerabilidad o exclusión, es decir la exclusión social es un proceso personal, único en donde los factores individuales inciden en la salud de las personas, en sus habilidades cognitivas y en su rendimiento escolar, todo ello además está determinado por su posición en el mercado de trabajo. ${ }^{54}$

La forma cómo opera este proceso estructural, de carácter multidimensional y multifactorial, en la vida de la ciudad durante la vigencia del Plano Regulador, se encuentra registrada en la prensa local. En este sentido cabe destacar las opiniones emanadas de la ciudadanía que los diarios de la época, 1948, recogía y divulgaba en sus publicaciones. Una de las quejas más frecuentes, contra la administración del distrito era la encaminada hacia el manejo de los servicios públicos en la ciudad, a lo cual se le endilgaba el evidente atraso y empobrecimiento de la ciudad en materia de espacio habitacional y ciudad industrial. El diario El Universal, de corte liberal, abre una sección, en la que realiza a sus lectores, una suerte de encuesta que permita medir el pulso de la ciudadanía ante las obras emprendidas en el distrito por la administración vigente, la encuesta cuenta con los siguientes interrogantes: "¿Cuales son en su concepto, los problemas fundamentales de la ciudad?. ¿A cuál de ellos concede usted mayor importancia y que formula más viable encuentra usted para superarlo?. ¿Cómo le parece la formación de un gran frente cívico para impulsar los destinos de la ciudad?. ${ }^{55}$

Las respuestas de la ciudadanía indicaban que las problemáticas más sentidas giraban en torno a: Planta Eléctrica, Aseo y Calle, Puerto y turismo, El Alcanta-

\footnotetext{
${ }^{54}$ M. Hernández P., Exclusión social y desigualdad, pp.38-47.

${ }^{55}$ AHC, El Universal, Cartagena, 4 de junio de 1948; Se expresan, además, en esta columna manifestaciones en cuanto a la negligencia de la administración distrital "de siempre".
} 
rillado y la energía eléctrica. ${ }^{56}$ Para la primera de las reclamaciones rastreamos lo que la prensa registra en materia de servicios públicos en la ciudad.

En el asunto de la energía eléctrica: En un editorial titulado Servicios Públicos el periódico llama la atención sobre el deficiente servicio que a través de los años ha prestado la Empresa de servicios Públicos Municipales en la administración de la planta eléctrica, adjudicándole a esto el enorme letargo que en materia industrial, portuaria y comercial ha tenido la urbe en muchos años. ${ }^{57}$ Así, también, se refiere el mismo diario a los problemas en cuanto a la prestación del servicio, incluso en zonas del interior del recinto amurallado. 58

De otra parte, y remitiéndonos a las recomendaciones hechas por el Plano regulador, contratado por la misma dirigencia distrital, para finales de año, se registra en el Consejo, la negligencia de las autoridades en cuanto al manejo, ubicación y mejoras requeridas para la planta eléctrica de la ciudad:

[...] Acuerdo para el ensanchamiento de la planta eléctrica, con la inversión de dineros del municipio, para obtener una mayor cobertura en el servicio de energía eléctrica, que permite. Hacer de la ciudad un sitio más atractivo para el establecimiento de industrias y empresas en la ciudad, debido a que en ocasiones anteriores se han perdido oportunidades de asentamiento de estos negocios por falta de una correcta prestación del servicio; el mejoramiento del bombeo del acueducto, lo que redundaría en mejor y mayor prestación de éste servicio a la ciudadanía; y finalmente la adecuación de escenarios públicos, tal como el estadio once de noviembre que en ese momento se está construyendo. La junta administradora de la Empresas Públicas Municipales, gestionara con el Departamento de Bolívar en cumplimiento de la Ordenanza número 126 de 194, sobre ensanchamiento de la Planta Eléctrica de Cartagena. Puesto en consideración es aprobado y adoptado; Artículo $6^{\circ}$. Declárese de GRAVE NECESIDAD PÚBLICA, el ensanche y mejoramiento de la Planta Eléctrica Municipal, para el progreso industrial de Cartagena, hoy estancado lamentablemente con perjuicio para la ciudad. Puesto en consideración, aprobado y adoptado. ${ }^{59}$

\footnotetext{
${ }^{56}$ AHC, El Universal, Cartagena, 4 de junio de 1948.

${ }^{57}$ AHC, El Universal, Cartagena, 5 de junio de 1948.

${ }^{58}$ AHC, El Universal, Cartagena, 4 de junio de 1948.

${ }^{59}$ AHC, Libro de Actas de los Anales del Concejo Municipal, Cartagena, 18 de noviembre de 1948p.40.
} 
Sin embargo estas consideraciones se reportan, también, en lo que a prestación del servicio de acueducto se refiere. En 1948 el Concejo municipal reglamenta la extensión del alcance de la tubería del actual acueducto hasta el final de la zona norte de la ciudad. Además del saneamiento de algunos pozos de recolección de "caseríos" que forman parte de la división político administrativa del distrito. Lo que se concluye es que el nuevo sistema de acueducto, para esta fecha, no es completo. Por ello esta corporación acuerda:

Artículo $3^{\circ}$. [...] la alcaldía de distrito procederá a hacer ante la Compañía de Servicios Públicos de Cartagena las gestiones necesarias para que la tubería moderna sea prolongada de las inmediaciones del Hotel Caribe, hasta donde llega en la actualidad, hasta el sitio del paraje llamado "El Laguito" final del barrio de Boca Grande, [...], a fin de que los habitantes de los caseríos de Tierra Bomba y Caño de Loro (sano), puedan llegar hasta allí a abastecerse de agua. E igualmente la Alcaldía dictara las medidas del caso para reparar convenientemente el pozo colonial de Tierra Bomba de donde venia proveyéndose la población. [...], puesto en consideración es aprobado y adoptado; [...] Construcción de amplios pozos artesianos en la población de Santana y el caserío de Ararca. ${ }^{60}$

Pero si la intención era que las medidas de modernización urbana, planeadas para la ciudad, fueran implementadas exclusivamente para el desarrollo de algunas zonas, y no para la totalidad del territorio de la urbe, entonces sí tuvieron un resultado positivo que mostrar.

Desglosemos de manera ordenada los puntos sugeridos por el Plano. Primero, en lo que tiene que ver con las vías carreteables, el Plano recomendaba la construcción de dos troncales que se convirtieran en la columna vertebral de la movilidad. La principal vía de la ciudad debía ser construida a partir de la antigua línea de rieles que ocupaba el ferrocarril Cartagena-Calamar.

La avenida Pedro de Heredia atravesaría el territorio de norte a sur, desde sus zonas de extramuros hasta la entrada de la península de Boca Grande. Esta vía se conectaría con las calzadas internas de la ciudad amurallada. Pero tal requerimiento no se operó en su totalidad. Meta que se lograría en 1963 gracias a la inicia-

\footnotetext{
${ }^{60}$ AHC, Libro de Actas de los Anales del Concejo Municipal, Cartagena, 18 de noviembre de 1948, pp.13-14.
} 
tiva del entonces gobernador Rafael Vergara Támara, ${ }^{61}$ quien se propuso la finalización de dicha obra, como ofensiva contra los habitantes de Chambacú quienes se habían resistido a su reubicación. Chambacú era un barrio de extrema pobreza que se hallaba en el trazado de la avenida, pero que además contrastaba con la estampa de ciudad turística. Sin embargo, en los sectores de la ciudad amurallada, las obras de ornato y arreglo de las calles internas se llevaron a cabo sin inconvenientes y más bien con celeridad, incluso solicitando para tal fin el concurso de los ciudadanos. ${ }^{62}$

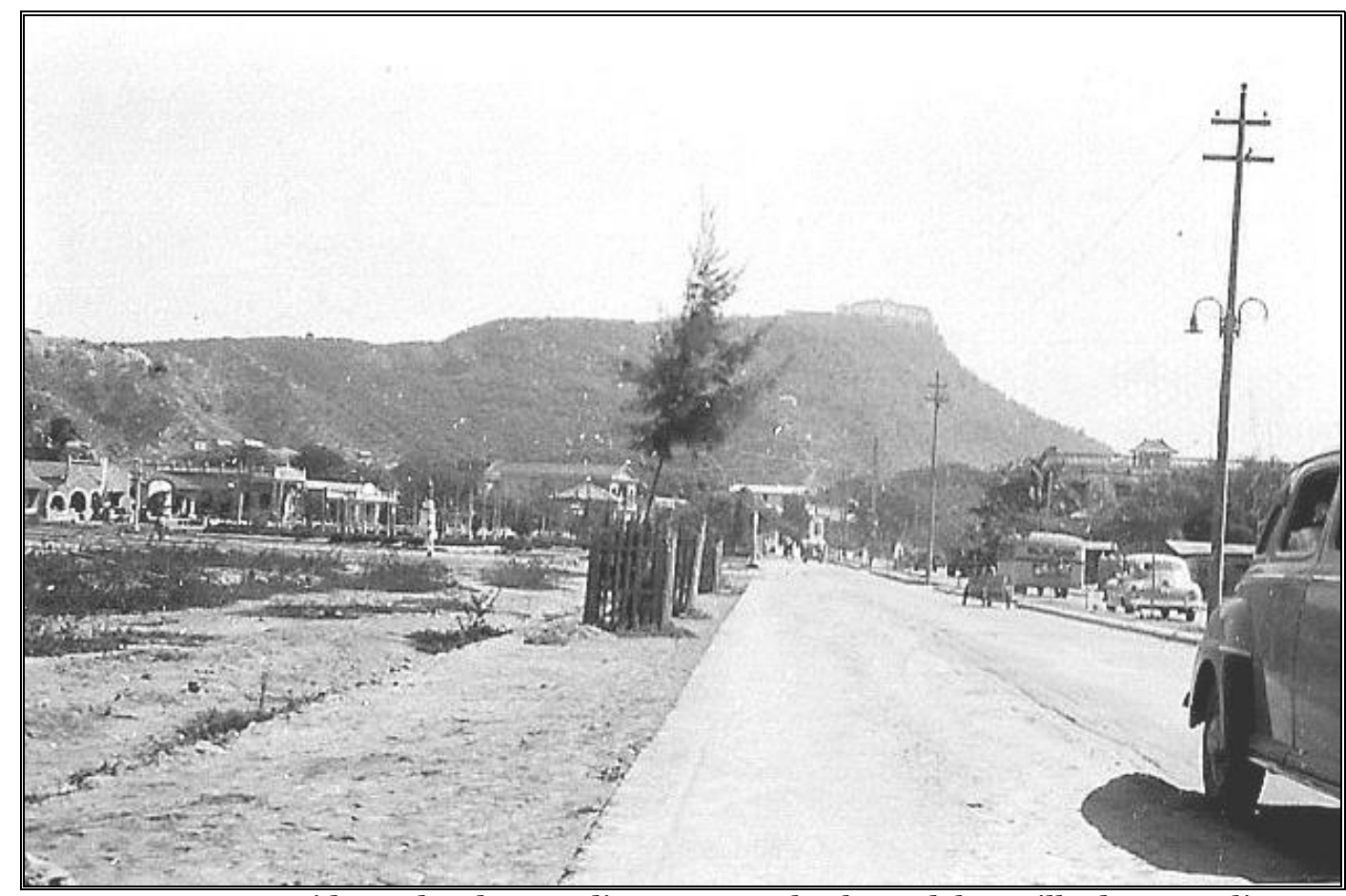

Imagen 13. Avenida Pedro de Heredia en 1949, a la altura del Castillo de San Felipe. (Colección particular).

Así mismo se propendía por el mejoramiento del entorno de los barrios de extramuros, pero donde se ubicaran familias de clase alta, como lo muestra un decreto emanado del consejo municipal: "Que se asfalte el callejón "Constantino Pare-

${ }^{61}$ Orlando de Ávila, Políticas Urbanas, Pobreza y Exclusión Social en Cartagena: el caso de Chambacú, Tesis de grado para optar el título de Historiador. Universidad de Cartagena, 2008, p.145.

${ }^{62} \mathrm{AHC}$, Libro de Actas de los Anales del Concejo Municipal, Decreto n. ${ }^{\circ} 12$ del Alcalde Mayor de Cartagena, Cartagena, 23 de enero de 1948, p.27. 
ja" y la avenida del Lago del barrio El Cabrero". ${ }^{63}$ En contraste, para los barrios de extramuros de las clases populares, las labores de aseo, pavimentación, prestación de servicios básicos y ornato, se demoraron un poco más.

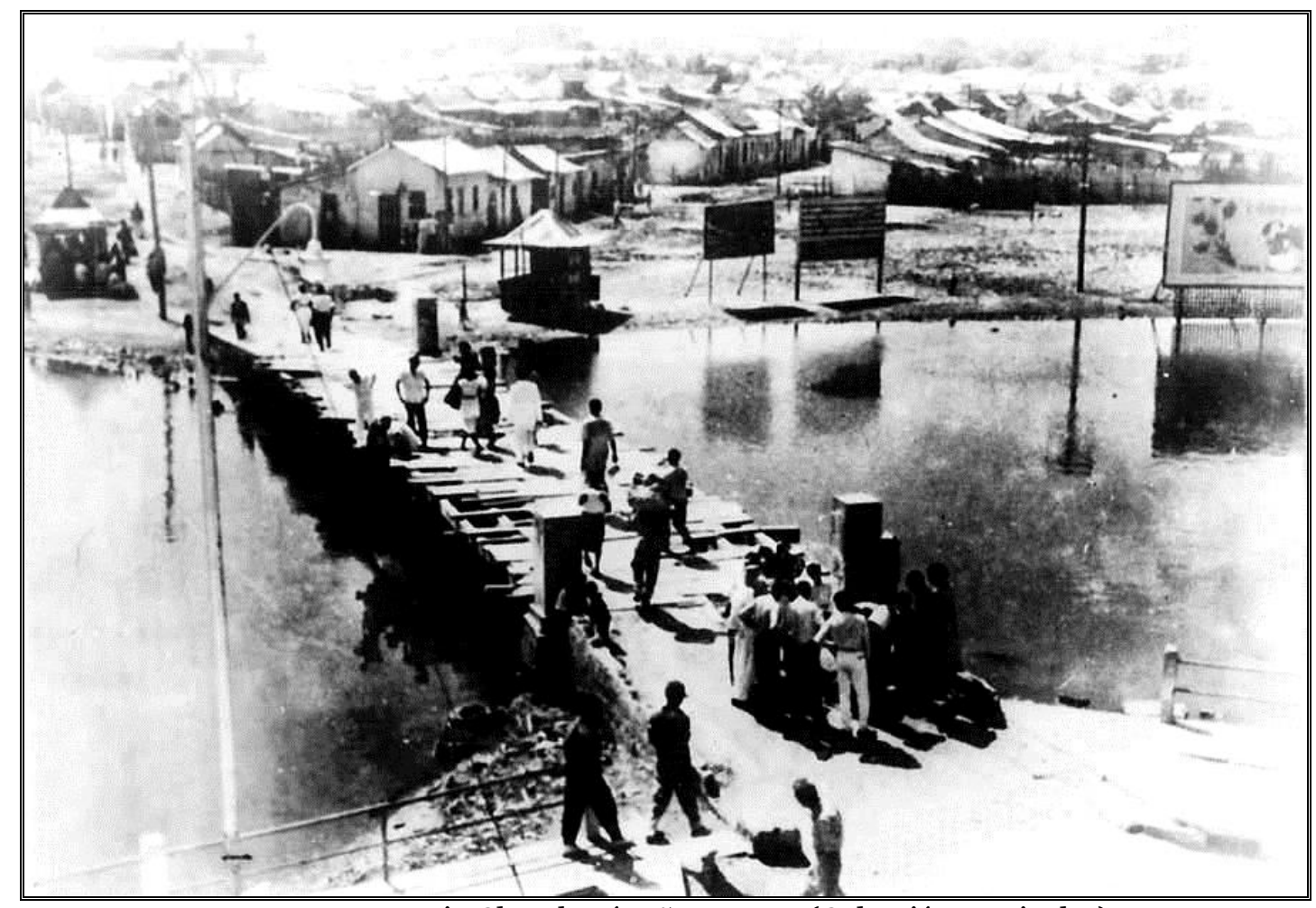

Imagen 14. Barrio Chambacú, años 1970s. (Colección particular)

Para el año de 1956, Chambacú, el barrio de extramuros que contenía el mayor número de familias, de mayor extensión territorial y más cercano a la ciudad amurallada, presentaba el siguiente cuadro urbanístico: "Adolecía de servicios básicos, de escuelas suficientes, de un puesto de salud permanente, el equipamiento urbano era precario, a-funcional, exiguo; en conclusión, la isla no reunía las mínimas garantías para que pudiera gestarse en sus predios una vida digna". ${ }^{64}$ Vale la

\footnotetext{
${ }^{63}$ AHC, Libro de Actas de los Anales del Concejo Municipal, Cartagena 18 de noviembre de 1948, p.15.

${ }^{64}$ Un detallado registro del proceso de establecimiento, vida y desarraigo del barrio de Chambacú, puede encontrarse en O. de Ávila, Políticas urbanas, p.44.
} 
pena recalcar que los barrios de Pekín, Pueblo Nuevo y Boquetillo, primeros asentamientos humildes por fuera del Corralito de Piedra, contiguos a la cortina de muralla de la zona oriental de la ciudad vieja, fueron trasladados a finales de la década del treinta. 65

Lo que llama la atención del caso de Chambacú, es que es el fiel reflejo de la problemática situación en la que se encontraban los barrios periféricos de la ciudad por causa del abandono y desidia de la administración local. Situación que, en parte, se debía a la preocupación por el desarrollo de modelos urbanísticos acordes al proyecto económico, dígase del sector turístico, para el cual la panorámica marginal, ofrecida por sectores y habitantes como los de Chambacú, funcionaban en contra vía de tal iniciativa. Pero lo que subyace de fondo, en este tipo de realidades que presentaba la urbe a mediados del siglo Xx, es que los sectores que no pertenecen al circuito de posibilidades del progreso económico y/o comercial de la ciudad son des-atendidos y menos cavados en la atención de sus condiciones básicas habitacionales y urbanísticas.

Siguiendo con esta línea de análisis podríamos citar, tal como lo recomendara el Plano Regulador en lo que a sector salud se refiere, el hospital Santa Clara y el hospital Militar, este último adosado a la Base Naval, fueron ampliados y modernizados en sus instalaciones. Cabe resaltar que el hospital Santa Clara se encontraba al interior de la zona del recinto amurallado de la ciudad, zona que, para la época, está presentando los niveles más elevados de valorización de terrenos, lo que en consecuencia genera la vecindad de familias adineradas. Así mismo, el Hospital Militar, se ubicaba en la entrada de la península de Boca Grande, zona destinada, por la administración distrital y nacional, como polo de desarrollo turístico y hotelero de la ciudad. Lo que se interpreta de estas "inversiones", en los centros de salud de primer nivel, es que la población a la que se destinaban los servicios de los dos centros hospitalarios, era de familias prestantes de la ciudad y de los visitantes que la iniciativa turística jalonaba. Mientras, en los barrios de extramuralidad, los servicios médicos, hospitalarios y de farmacia brillaban por su ausencia.

De otro lado, lo que se planeó con la zonificación de la ciudad fue crear condiciones urbanas que le brindaran a la Cartagena de 1948 la posibilidad de articular las dimensiones sociales, económicas y laborales de cada uno de los sectores. Con esto se posibilitaría un entorno social capaz de generar espacios de crecimiento,

${ }^{65}$ AHC, El Fígaro, Cartagena, 5 de julio de 1939. 
desarrollo y modernidad compartidos y comprometidos con la mayoría, sino con la totalidad de los habitantes del territorio. Condiciones que eran de esperarse tanto en el tiempo de ejecución del Plano Regulador, como en la proyección futura de la ciudad, como se deja ver cuando se expone el plan vial: "[...] y al mismo tiempo, vayan siendo practicables con los cursos de Cartagena, a medida que vaya progresando demográficamente y económicamente". ${ }^{66}$ Pero la realidad que se observa al realizar el barrido de los hechos, es que la Cartagena turística, la Cartagena industrial y la Cartagena de hijos de vecino, conforman un territorio abismalmente fragmentado y des-articulado.

El crecimiento industrial de la ciudad, a partir del desarrollo de las empresas ubicadas en el sector de Mamonal no vinculó un número importante de habitantes de la urbe a sus negocios: En 1951, no más del 24\% de la población activa de la ciudad estaba vinculada al sector industrial. Durante toda la mitad del siglo xx esta cifra se ha venido en franca decadencia, hasta el punto en que en 1997, asciende al $7.7 \%$ de la población activa. ${ }^{67}$ Lo que también registra un periodista del Diario de la Costa para 1965:

Cientos de obreros y empleados, en su mayoría hombres de bien y capacitados, buscan trabajo en las nuevas fábricas e industrias y, en porcentajes que ellos calculan de 78 por ciento, de enero de 1964 a la fecha, han sido rechazados, por gerentes que naturalmente tampoco son de Cartagena y que actúan como simples delegatarios de entidades con asiento en Bogotá y otras ciudades del país. ${ }^{68}$

Una de las razones que podrían dar cuenta de esta exclusión, por parte del sector industrial de Mamonal, para con la población humilde de Cartagena, se fundamenta en la especificidad laboral que se abría en este sector productivo. La industria que se practicaba en Mamonal correspondía al sector petroquímico, el cual requiere un porcentaje de ocupación en mano de obra considerablemente bajo, debido a la mecanización del proceso factorial en sí. De otra parte el personal reque-

\footnotetext{
${ }^{66}$ A. P., Memoria explicativa del Plano Regulador de José María González Concha, p.28r.

${ }^{67}$ J. Báez y H. Calvo, "La economía de Cartagena en la segunda mitad del siglo xx: Diversificación y rezago", pp.14-33.

${ }^{68}$ J. Báez y H. Calvo, "La economía de Cartagena en la segunda mitad del siglo Xx: Diversificación y rezago", pp.14-33.
} 
rido por esta actividad demanda la cualificación a nivel técnico y tecnológico, lo que para la época, dadas las condiciones deplorables en el campo educativo y formativo, resultaba nulo en la población de extracción humilde de la ciudad.

Es así, que los habitantes de las barriadas de la urbe se ven desligados del sector industrial de la ciudad. Sector que en el aspecto geográfico de Cartagena, se ubica en el extremo sur-occidental de su territorio. Al lado de esta zona de producción fabril, en años posteriores, se desarrollarían barrios sub-normales, como resultado del explosivo y caótico crecimiento urbano que se generó a partir de la masiva migración de gentes del campo a la ciudad, atraída por la posibilidad de vincularse al circuito laboral de las empresas establecidas en dicho sector. Se conforman, entonces, tugurios y barrios de miseria, llamados invasiones, donde la carencia de servicios básicos, planeación y equipamiento urbano fue su rasgo característico. Una consecuencia de este modelo de dinámica poblacional es que aún, en el siglo XXI, muchos de estos asentamientos humanos presentan el mismo cuadro de abandono y miseria de hace cincuenta años.

El otro gran componente de proyección económica para Cartagena, planteado por las elites locales y nacionales, fue el establecer a la ciudad como destino turístico de primer nivel, tanto a nivel nacional, como internacional. Para ello, la administración distrital, emprende una masiva campaña publicitaria, expresada a través de guías turísticas, canciones, folletos promocionales, libros, estampas, etc. que venden a la ciudad como Paraíso Tropical. ${ }^{69} \mathrm{En}$ el aspecto paisajístico del $\mathrm{Co}$ rralito de Piedra se adelanta un plan de ornato y adecuación de los espacios arquitectónicos y urbanísticos de la ciudad, en el que se incluye la limpieza y arreglo de las fortificaciones y edificaciones coloniales, la pavimentación de calles, la higienización de algunos sectores, el arreglo y arborización de parques y plazas; y la "reubicación” de todos aquellos elementos que afearan la estampa de Ciudad Tropical.

\footnotetext{
${ }^{69}$ Es curiosa la imagen que se percibe de la ciudad por los habitantes del interior del país. Noches de Cartagena, famosa canción que hace alusión a los encantos de la ciudad, compuesta por el antioqueño Jaime R. Echavarría, sale a la luz durante los años sesentas, cuando inicia todo un proyecto agresivo por fortalecer la industria del turismo . Nótese que la mirada que se tiene de Cartagena es la de una ciudad tropical, de brisa y mar que además guarda todo un encanto colonial. Es la imagen de una ciudad que empieza a configurarse como escenario nacional para el turismo. Sobre su pasado colonial ahora se superpone un paisaje tropical que hace de la ciudad el lugar propicio para la experiencia idílica y romántica. Desde esta mirada lo que cuenta es el tiempo y el espacio, los grupos humanos que habitan la ciudad y la dinamizan son excluidos o invisibilizados; en esta misma línea encontramos canciones como: Cartagena Letra de Leónidas Otálora y música de Adolfo Mejía; Callecitas de Cartagena de Arabella y, Noches de Cartagena, de Jaime Echavarría.
} 
El caso de mayor impacto, de esta iniciativa de arreglo del paisaje de la urbe, lo constituyó el traslado del barrio de Chambacú, vecino inmediato del sector amurallado, hacia las zonas más alejadas posibles del sector del Centro y de la península de Boca Grande, emporios del planeado desarrollo turístico. ${ }^{70}$

Esta campaña de adecuación del entorno de la ciudad, no solo se limitó a suprimir del paisaje los elementos de suciedad y antihigiénicos, ${ }^{71}$ sino que también dio cuenta de todos aquellos cuadros de pobreza y marginalidad que pudieran deprimir el goce del visitante. La mejor manera que encontraron las autoridades locales para controlar esta situación fue segregar a los pobladores marginados, del sector turístico. Para lograr tal propósito, a través de la prensa local, se generó el imaginario del miedo hacia la gente de Chambacú. En el imaginario colectivo la mayoría de los chambaculeros, ya por su condición racial, representaban los anti-valores de una cultura blanca y europea.

Tal vez una de las causas a las que podamos atribuir el desprecio que las elites locales sentían por Chambacú sea, además de su situación de miseria y abandono, su ubicación geográfica en la ciudad. La cercanía que presentaba la barriada con el Centro Histórico Amurallado, distaba escasos 100 metros, lo que la convertía en blanco fácil del ejemplo de la contracultura que la elite combatía, pero que requería, para reafirmarse como cultura superior.

Por otra parte, Chambacú era el barrio de mayor extensión territorial de la ciudad. Dicho barrio fue el destino de millares de seres humanos que, debido a la trashumancia, tanto intra como inter urbana, densificaron su interior, lo que daba como resultado una elevada concentración de personas ocupando un sector que adolecía del equipamiento y las condiciones mínimas para el desarrollo de una vida

\footnotetext{
70 O. de Ávila, Políticas urbanas, pp.93-97.

${ }^{71}$ En cuanto a la vinculación de los marginados al sector turístico, a través de la informalidad, en una carta enviada por un ciudadano al periódico El Universal, se leía que: "Creo que a ninguna vista se ha escapado, a excepción de los funcionarios de la Higiene, el horrendo conjunto de suciedad que constituyen ciertos carritos en los que se expenden Ostras, bebidas heladas y golosinas, y no menos sucios están quienes ejercen tal oficio, y todo con perjuicio de la salud del pueblo que consume tales porquerías, saturadas de un inconcebible número de microbios [...]”. AHC, Prensa, El Universal, Cartagena, 2 de junio de 1948.
} 
digna. ${ }^{72}$ Chambacú fue, entonces, la versión criolla de La Ciudad de la Alegría, despreciada por los dueños del poder y amada por sus gentes humildes. ${ }^{73}$

Pero, si bien Chambacú se convierte en el referente más visible de la segregación y exclusión de que fueron objeto los sectores marginados del proyecto turístico, la realidad para otros barrios de la periferia de la ciudad no era diferente, tal como lo señala un escrito que aparece en la prensa local:

Nos hemos acostumbrado los cartageneros a hablar solamente de Chambacú. Y parecería que solo cuando en las calendas grietas se resulta el problema de esa isla, será cuando volvamos los ojos compasivos a mirar en que viven esos nuevos barrios que llamamos de oriente, donde las viviendas de las clases pobres son tan ominosas como las de la mayoría de Chambacú. Allá también hay que hacer algo, planear algo, legislar o acordar algo. Esas barriadas que sueñan con el pomposo nombre de "Boston", "La Esperanza", "Amberes" etc., y las que se van extendiendo sin nombre aun conocido en las faldas de la Popa, albergan una muchedumbre de gentes abandonadas por Dios y la sociedad. ${ }^{74}$

Tal vez por no hacer parte de la vista panorámica inmediata de los balcones y de los edificios de los hoteles de Boca Grande, estos otros barrios no fueron tan señalados por la dirigencia local. Es más, podría asegurarse que mientras se mantuvieran por fuera de la zona de tránsito del sector turístico, podrían continuar con su ordinaria cotidianidad y servir como receptáculo de la población reubicada de las inmediaciones del área de interés. ${ }^{75}$ Chambacú había desaparecido físicamente, pero el espíritu de la marginalidad, seguía aleteando sobre el territorio de la urbe.

Sin embargo, las dos realidades sociales seguían coexistiendo en el mismo espacio. Pese a los esfuerzos de las administraciones nacionales y distrital, los habitantes pobres, miserables, excluidos y abandonados de la ciudad no desaparecían,

\footnotetext{
72 O. de Ávila, Políticas urbanas, pp.32-61.

${ }^{73}$ Domique Lapierre, La Ciudad de la Alegría, Barcelona, Ed. Plaza, 2007, p.386

${ }^{74}$ O. de Ávila, Políticas urbanas, p.58

${ }^{75}$ Para una mirada completa sobre la situación de la conformación de los barrios de extramuros de Cartagena a lo largo del siglo Xx consultar a Carmen Cabrales, "Los Barrios Populares de Cartagena”, en Haroldo Calvo Stevenson y Adolfo Meisel Roca (comps.), Cartagena de indias en el siglo XX, Bogotá, Banco de la República, 2000, pp.181-209.
} 
por muy lejos que los ubicaran del encuadre de la fotografía que los turistas tomaran. Seguían estando en el aroma que la ciudad respiraba. No obstante el estado de marginalidad, en el que se hallaba la mayor parte de la ciudad, estos sectores, o pobladores, asumieron diversas estrategias de resistencia ante la exclusión producto del modelo económico puesto en marcha, como el proyecto de ciudad moderna que se jalonaba. Lo que estaba en juego para este otro sector de la ciudad, no era una variable en su proyecto de vida, lo que se jugaban las clases marginadas de Cartagena era su derecho a la vida digna en medio de una ciudad que los excluía.

Como resultado de estas estrategias de apego a la vida, el habitante popular de Cartagena desarrolló una significativa actividad informal, a través de las ventas ambulantes, los oficios varios y el sub-empleo, derivado de la actividad turística, comercial e industrial, pero, sin lograr vincularse formalmente a ninguno de estos sectores.

De la misma manera como la industria requería trabajadores calificados para laborar en sus dependencias, el sector turístico necesitaba que sus empleados contasen con cierto grado de formación en habilidades como el manejo de idiomas, atención al visitante y de las competencias laborales propias de una industria turística que pretendía equipararse a la de otros destinos turísticos del Caribe. No obstante, a los requerimientos formativos, solo podían acceder quienes gerenciaban el proyecto turístico, pues la población que constituía los sectores marginados de la urbe, en su mayoría, no alcanzaba a completar su formación en educación básica.

Este otro factor se instituía como un elemento más de exclusión social, y de alejamiento de la posibilidad de encontrar cabida en el segundo modelo económico de la ciudad. La lectura que queda de este comportamiento social fragmentario, es el de una gran masa poblacional desligada de toda oportunidad de integrarse a un modelo de ciudad pensada y planeada por sus dirigentes. Sustentada en principios modernizadores, orquestados en un solo sentido, emanados de un discurso unidireccional y unifuncional. $O$ funcional en el macabro sentido de coaptar las posibilidades de acceso de "los otros", para poder legitimar el accionar excluyente de la clase y la cultura hegemónica.

\section{Conclusión}

Lo que se pude concluir, del recorrido panorámico por las recomendaciones y aplicaciones del Plano Regulador de 1948, es que la ciudad de Cartagena, a partir de la 
segunda mitad del siglo xx, profundiza sus rasgos de ciudad dual. Fragmentación que se observa en la aplicación parcial de lo planeado, sobre todo en los sectores de la urbe en donde se ubicaban pobladores de la clase pudiente. Pero además, la diversificación económica lograda no facilitó el acceso de las clases populares a los beneficios derivados de actividades como el comercio, la industria y el turismo. En la práctica no se ejecutó lo concerniente a las modalidades educativas técnicas y tecnológicas que favorecieran la vinculación de los pobres de la ciudad a la oferta laboral que se abría con el impulso de los sectores antes señalados.

Las posibilidades de acceso a servicios de salud y domiciliarios básicos, para los barrios de la periferia, seguía siendo tan precaria como en los inicios del siglo. Los centros médicos en los barrios, el agua potable, el alcantarillado y el servicio de energía eléctrica, en condiciones eficientes, fue un anhelo de los cartageneros del común que debió irremediablemente aplazarse. En consecuencia el aspecto que adquirieron "los barrios pobres" del extramuro fue el de tugurios o de "alojamientos ilegales".

Una última reflexión que se extrae de la exploración adelantada por el Plano Regulador hace referencia a la exclusión como un proceso de larga duración en la ciudad. Conjuntamente, con las características arriba señaladas, la exclusión en la ciudad operó por cuenta del alejamiento relacional de los sectores populares de los procesos modernizadores. El ejemplo de Chambacú da cuenta de una modernización en la que no cuentan los pobres, más bien ellos son un obstáculo para alcanzarla.

\section{Bibliografía}

\section{Fuentes primarias}

Archivo Histórico de Cartagena, Fondo Prensa:

Diario Oficial, Bogotá, 1948.

El Fígaro, Cartagena, 1939.

El Universal, Cartagena, 1948.

Fondo Consejo

Libro de Actas de los Anales del Concejo Municipal, Cartagena 18 de noviembre de 1948. 
Libro de Actas de los Anales del Concejo Municipal, Acuerdo $\mathrm{n}^{\circ}{ }_{2}$, Cartagena, 29 de febrero de 1948.

Libro de Actas de los Anales del Concejo Municipal, Cartagena, 18 de noviembre de 1948.

Libro de Actas de los Anales del Concejo Municipal, Decreto n. ${ }^{\circ} 12$ del Alcalde Mayor de Cartagena, Cartagena, 23 de enero de 1948.

Libro de Actas de los Anales del Concejo Municipal, Cartagena, 18 de noviembre de 1948Pág. 40.

Archivo personal, Memoria explicativa del Plano Regulador de José María González Concha. (Documento cedido por la historiadora María Teresa Ripoll).

Directorio industrial y comercial de Bolívar, Cartagena, ANDI, 1982.

\section{Fuentes secundarias}

Álvarez Medina, Alfonso, "Problemas de investigación en "Historia urbanística”, en Historia Urbana. Revista de historia de las ideas y de las transformaciones urbanas n. ${ }^{\circ}$, Valencia, Universidad Politécnica de Valencia, 1992.

Álvarez Medina, Alfonso, "La necesaria componente espacial en la historia urbana”, en Carlos Sambricio, (ed.), La historia Urbana, Colección Ayer n. ${ }^{\circ} 23$, Madrid, Marcial Pons, 1996.

Ávila, Orlando de, Políticas Urbanas, Pobreza y Exclusión Social en Cartagena: el caso de Chambacú, Tesis de grado para optar el título de Historiador Universidad de Cartagena, 2008.

Báez, Javier y Calvo Stevenson, Haroldo, "La economía de Cartagena en la segunda mitad del siglo XX: Diversificación y rezago", en Haroldo Calvo Stevenson y Adolfo Meisel Roca (eds.), Cartagena de indias en el siglo XX, Bogotá, Banco de la República, 2000.

Cabrales, Carmen, "Los Barrios Populares de Cartagena", en, Haroldo Calvo Stevenson y Adolfo Meisel Roca (eds.), Cartagena de indias en el siglo XX, Bogotá, Banco de la República, 2000, pp.181-209.

Espinosa, León Darío, "El Plan Piloto de Cali 1950”, en Bitácora n. ${ }^{\circ} 10$, Bogotá, Universidad Nacional, 2006, pp.222-232.

Fonseca, Lorenzo y Saldarriaga, Alberto, "Aspectos de la arquitectura colombiana del siglo Xx”, en Carlos Castillo (comp.), Urbanismo y vida urbana, Instituto colombiano de cultura, Bogotá, 1977. 
Fuente, María de Jesús, Diccionario de historia urbana y urbanismo. El lenguaje de la ciudad en el tiempo, Madrid, Universidad Carlos III de Madrid, 1999.

Gualteros Trujillo, Nicolás, (ed.), Itinerarios Urbanos: París, La Habana, Bogotá: narraciones, identidades y cartografía, Bogotá, Universidad Javeriana, 2006.

Hernández, Carmen y Bohórquez, Nellys. Barrios populares. Una forma de construir ciudad en Cartagena de Indias. Casos: Pekín, Pueblo Nuevo y Boquetillo 189o-1939, Tesis de grado, Universidad de Cartagena. 2008.

Hernández Pedreño, Manuel. Exclusión social y desigualdad, Murcia, Universidad de Murcia, 2008.

Krieger, Peter, Paisajes Urbanos: Imagen y memoria, México UNAM, 2006.

Lapierre, Domique, La Ciudad de la Alegría, Barcelona, Ed. Plaza, 2007.

Mejía Pavony, Germán, "Pensando la Historia Urbana", en Germán Mejía y Fabio Zambrano (eds.), La ciudad y las Ciencias Sociales. Ensayos y aproximaciones, Bogotá, Universidad Javeriana, 2000.

Munford, Lewis, La ciudad en la historia, su origen, transformaciones y perspectivas (Colmena o ciudad), tomo II, Eds. Infinito, 1996.

Sassen, Saskia, Territorio, Autoridad y Derechos. De los ensamblajes medievales a los ensamblajes globales, Madrid, Katz Editores, 2010.

Seta, Cesare de, La ciudad europea del siglo XV al XX, Madrid, Ed. Istmo, 2002.

Suárez Mayorga, Adriana. La ciudad de los elegidos. Crecimiento urbano, jerarquización social y poder político. Bogotá (1910-1950), Bogotá, Ed. Guadalupe Ltda., 2006.

Torres Tovar, Carlos, "Reflexiones sobre el contexto del urbanismo en Colombia" en Urbanismo, maestría en urbanismo. pp.122-137. http://goo.gl/pRNroM. (Consulta: 27 de octubre de 2011). 